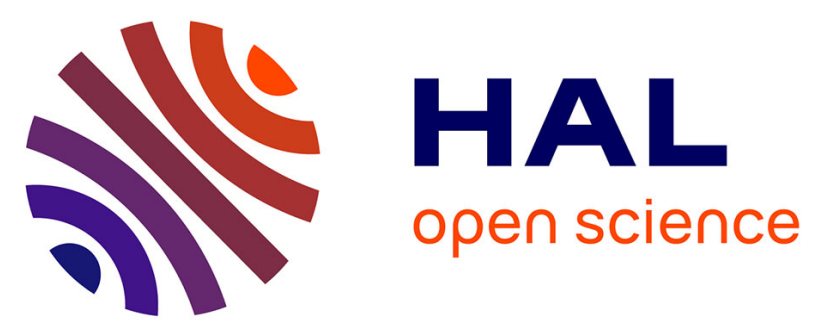

\title{
An evaluation of uncertainties in monitoring middle atmosphere temperatures with the ground-based lidar network in support of space observations
}

Philippe Keckhut, W. J. Randel, Chantal Claud, Thierry Leblanc, Wolfgang Steinbrecht, Beatriz M. Funatsu, Hassan Bencherif, I. Stuart Mcdermid, Alain Hauchecorne, C. Long, et al.

\section{To cite this version:}

Philippe Keckhut, W. J. Randel, Chantal Claud, Thierry Leblanc, Wolfgang Steinbrecht, et al.. An evaluation of uncertainties in monitoring middle atmosphere temperatures with the ground-based lidar network in support of space observations. Journal of Atmospheric and Solar-Terrestrial Physics, 2011, 73 (5-6), pp.627-642. 10.1016/j.jastp.2011.01.003 . hal-00560268

\section{HAL Id: hal-00560268 https://hal.science/hal-00560268}

Submitted on 25 Oct 2016

HAL is a multi-disciplinary open access archive for the deposit and dissemination of scientific research documents, whether they are published or not. The documents may come from teaching and research institutions in France or abroad, or from public or private research centers.
L'archive ouverte pluridisciplinaire HAL, est destinée au dépôt et à la diffusion de documents scientifiques de niveau recherche, publiés ou non, émanant des établissements d'enseignement et de recherche français ou étrangers, des laboratoires publics ou privés. 


\title{
An evaluation of uncertainties in monitoring middle atmosphere temperatures with the ground-based lidar network in support of space observations
}

\author{
P. Keckhut a,*, W.J. Randel ${ }^{\text {b }}$, C. Claud ${ }^{\text {c }}$, T. Leblanc ${ }^{d}$, W. Steinbrecht ${ }^{e}$, B.M. Funatsu ${ }^{a, c}$, H. Bencherif ${ }^{f}$, \\ I.S. McDermid ${ }^{\mathrm{d}}$, A. Hauchecorne ${ }^{\mathrm{a}}$, C. Long $^{\mathrm{g}}$, R. Lin ${ }^{\mathrm{g}}, \mathrm{G}$. Baumgarten ${ }^{\mathrm{h}}$

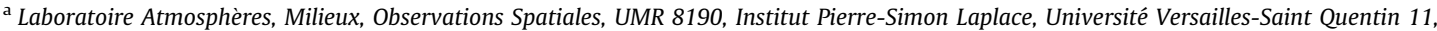 \\ boulevard d'Alembert 78280 Guyancourt, Verrières-le-Buisson, France \\ ${ }^{\mathrm{b}}$ National Center for Atmospheric Research, Boulder, CO, USA \\ ${ }^{\mathrm{c}}$ Laboratoire de Meteorologie Dynamique, UMR 8539, Institut Pierre-Simon Laplace, Ecole Polytechnique, France \\ d California Institute of Technology, Jet Propulsion Laboratory, Wrightwood, CA, USA \\ ${ }^{\mathrm{e}}$ Meteorologisches Observatorium, Hohenpeissenberg, Germany \\ ${ }^{\mathrm{f}}$ Laboratoire de l'Atmosphère et des Cyclones, UMR 8105, Université de La Réunion, St-Denis, France \\ ${ }^{\mathrm{g}}$ Prediction Center, NCEP, National Weather Service, NOAA, Camp Springs, USA \\ h Leibniz-Institute of Atmospheric Physics, Kuehlungsborn, Germany
}

\begin{abstract}
A B S T R A C T
The capability of the longest lidar data sets to monitor long-term temperature changes have been evaluated through comparisons with the successive Stratospheric Sounder Units (SSU) onboard NOAA satellites. Cross-consistency investigations between SSU and the lidar network can be considered as a first attempt to demonstrate how the synergistic use of space and ground-based instruments could provide reliable monitoring of the temperature of the middle atmosphere. The breakdown of the temperature cooling trend, and the following flattening observed in the satellite temperature series, is qualitatively confirmed by the lidars. However, there are still large differences that can either be due to SSU continuity (orbit drifts or weighting function modifications) or lidar operation changes (time of measurements, accuracy, sampling, etc.). SSU vertical weighting functions have been taken into account for comparisons. Some discontinuity events cannot be explained by the SSU weighting function drifts due to $\mathrm{CO}_{2}$. For the upper channels of SSU (peaking around $50 \mathrm{~km}$ ), the results are probably sensitive to the mesospheric part of the lidar profiles that can explain some discontinuities. Tropical lidar stations show clear inter-annual differences with the SSU channels covering the lowest altitude range that needs further investigations to understand if the origin is instrumental or geophysical. An attempt to derive non-linear trends with combinations of linear, hockey stick, and quadratic functions has been made. While the quadratic term is not highly significant, this approach allows the derivation of a better quantification of the linear trend terms.
\end{abstract}

\section{Introduction}

The temperature evolution of the middle atmosphere is an important parameter as a fingerprint of different anthropogenic forcing and also because the temperature plays a key role in the atmospheric composition and dynamics that can directly or indirectly impact the climate. In the middle and upper stratosphere, both the increase in well-mixed greenhouse gases and changes in ozone contribute to a temperature cooling of around

\footnotetext{
* Corresponding author. Tel.: +331 802852 50; fax: +331442737 76 .

E-mail address: Keckhut@latmos.ipsl.fr (P. Keckhut).
}

$1 \mathrm{~K} /$ decade (Ramaswamy et al., 2001; Eyring et al., 2006; Randel et al., 2009). These changes are an order of magnitude larger than what is expected at ground level (Rind et al., 1990). However, at altitudes above the lower stratosphere, there are quantitative differences between the modeled and observed cooling. The reduction of the anthropogenic chlorine loading in the atmosphere during the last decades let us expect an ozone recovery that will last during the next half century (WMO, 2006). Some indications of the start of this recovery have already been observed (e.g. Steinbrecht et al., 2006). The cooling rates in the upper stratosphere and lower mesosphere are then expected to be reduced by a factor of around 2 . However, the timing of the ozone recovery is questionable and can be influenced by climate 
feedbacks on the stratosphere. Temperature trends in the middle atmosphere remain an important issue because of the remaining uncertainty, and also because numerical climate models have made large improvements in extending their vertical altitude range and resolution and need accurate trend observations for their evaluation (Eyring et al., 2006; Austin et al., 2009).

The only globally coherent source of temperature measurements in the middle atmosphere on a long-term basis (decades) is provided by the successive Stratospheric Sounder Unit (SSU) instruments. Since late 1978, a series of TOVS (TIROS-Operational Vertical Sounders) instruments, which includes SSU, has been put into orbit onboard successive National Oceanic and Atmospheric Administration (NOAA) TIROS-N operational satellites. These SSU instruments do not yield identical radiance measurements for a variety of reasons and derived temperatures may change substantially when a new instrument is introduced (Gelman et al., 1986; Nash and Forrester, 1986). To overcome these limitations, a methodology has been developed by Nash and Forrester (1986) to produce adjusted zonal temperature series. Because it is the only near-global measurement of temperature in the upper stratosphere over such a long period, and in spite of the aforementioned limitations, an SSU has been extensively used for determining trends and understand their origins (Ramaswamy et al., 2001; Cagnazzo et al., 2006; Randel et al., 2009).

The temperature profile in the middle atmosphere has been observed over decades using systematic meteorological rockets from several specific sites (Kokin et al., 1990; Keckhut et al., 1999; Keckhut and Kodera, 1999; Kubicki et al., 2006; Kubicki et al., 2007). However, over the last decade, the main rocket programs conducted by the USA, the former Soviet Union, and Japan have ceased. More recently the Rayleigh lidar technique has been developed (Hauchecorne and Chanin, 1980) and systematic long-term measurements have been ongoing since 1991 within the Network for the Detection of Atmospheric Composition Change (NDACC), previously named the Network for the Detection of Stratospheric Change (NDSC; Kurylo and Solomon, 1990). While the trends derived from these data sets are very valuable in providing independent trend estimates, the sparse horizontal sampling from ground-based networks does not permit the derivation of global trends. However, such data does provide coherent long-term series of temperature profiles that can be used to evaluate the continuity of measurements made from space and their successive adjustments when a new satellite operates as a substitute of the previous one. Lidar systems running over more than a decade are however not free of instrumental changes, which may affect the measurement continuity. Inter-comparisons using a mobile lidar system have been used to check the homogeneity of the network (Keckhut et al., 2004); however, these campaigns are not performed frequently enough to detect any long-term drifts. Space/ground-based intercomparisons are highly valuable for such a mutual benefit. This proposed approach is not specific to the temperature of the middle atmosphere, as it is applied on all the NDACC instruments and is part of the international strategy that will be coordinated through the Global Earth Observing System of Systems (GEOSS) and described in its implementation plan (Battrick, 2005).

The most recent stratospheric temperature trend assessment (Randel et al., 2009) identifies even more instrumental and methodology issues than the previous one (Ramaswamy et al., 2001) as well as the break off in some data series (Randel et al., 2004) such as the stratospheric analyses at Berlin, rocketsonde, or SSU series. In the mesosphere, the situation is even worse as longseries are limited and highly disparate (Beig et al., 2003). In addition, while the two decades of observations from 1978 to 1998 show a quite linear cooling of the middle atmosphere, future trends can no longer be considered as linear continuous changes, which complicate their determination.
In this study, we compare SSU data sets with long temperature lidar data sets in order to:

i. evaluate the coherence of the lidar network,

ii. identify discontinuities in both SSU and lidar series,

iii. better estimate the methodology and the associated uncertainties in deriving temperature trends from observations,

iv. identify the domains, where improvements and further investigations are required.

The longest lidar data series at mid-latitude have been analyzed, taking into account the obvious non-linear long-term evolution of the temperature. In the first two sections, SSU temperature series and lidar data are described. In the third section, SSU series are compared with individual lidar series. In the following section, trends are derived from the lidar series. Finally some conclusions are drawn concerning the coherence of the long-term evolution in the upper stratosphere-mesosphere region and the latest trend estimates are discussed.

\section{Description of the SSU series}

SSU-based temperature analysis of the NOAA/NCEP (National Center for Environmental Prediction) is available for the period 1979 through 2005 (the last available SSU instrument was launched on NOAA-14 in 1996). The SSU data set consists of $10^{\circ}$ zonal brightness temperature anomalies from three observed $(25,26$, and 27$)$ and five synthetically derived (47X, 36X, 35X, $26 \mathrm{X}$, and 15X) channels having their maximum sensitivity at different altitudes as given in Table 1 . The weighting functions for the SSU channels are typically $10-15 \mathrm{~km}$ wide (Nash, 1988) with long tails, while the weighting functions for the synthetic channels using the off-nadir $\left(5^{\circ}\right)$ mode are somewhat sharper, see, for example, Fig. 1 of Randel et al. (2009). One complication with these satellite data is the discontinuities in the time series, due to measurements being made by different satellites monitoring the stratosphere since 1979. The last operational SSU on an NOAA 14 has a large overlap with an NOAA 11 . However, the orbit drift of the NOAA 14 caused the equatorial crossing time to change from 14:00 to around 21:00 UT, which brings about another source of data uncertainty. While estimates for correction of, and attempts to remove biases due to, longitudinal orbit drifts have been made this factor does introduce a potential uncertainty in the trend determination. Adjustments have been made using the so-called "Nash" methodology (Nash and Forrester, 1986) to compensate radiometric differences, tidal differences between spacecraft, longterm drift in the local time of measurements, and spectroscopic drift in channels 26 and 27. Several corrections have been made to account for these uncertainties. This was only possible in producing zonal mean values for $10^{\circ}$ latitudinal band from $70^{\circ} \mathrm{N}$ to $70^{\circ} \mathrm{S}$ back to 1978. An NOAA has produced continuous temperatures series following the "Nash" methodology.

Table 1

Peak altitudes of weighting functions of the SSU channels: near nadir viewing, and synthetic (combined near nadir and $35^{\circ}$ scans) extracted from Nash (1988).

\begin{tabular}{lrll}
\hline Channel type & Channel name & $\begin{array}{l}\text { Peaking pressure } \\
\text { level }(\mathbf{h P a})\end{array}$ & $\begin{array}{l}\text { Peaking altitude } \\
\text { level }(\mathbf{k m})\end{array}$ \\
\hline Synthetic & $15 \mathrm{X}$ & 80 & 23 \\
Near nadir & 25 & 30 & 29 \\
Synthetic & $26 \mathrm{X}$ & 15 & 35 \\
Near nadir & 26 & 4 & 38 \\
Near nadir & 27 & 2.5 & 44 \\
Synthetic & $36 \mathrm{X}$ & 2 & 45 \\
Synthetic & $47 \mathrm{X}$ & 1 & 50 \\
\hline
\end{tabular}




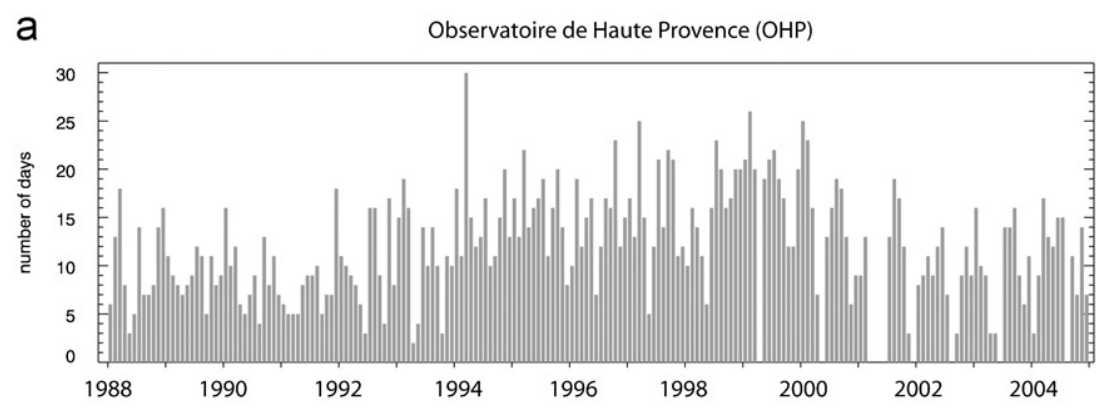

b Hohenpeissenberg Observatory $(\mathrm{HOH})$
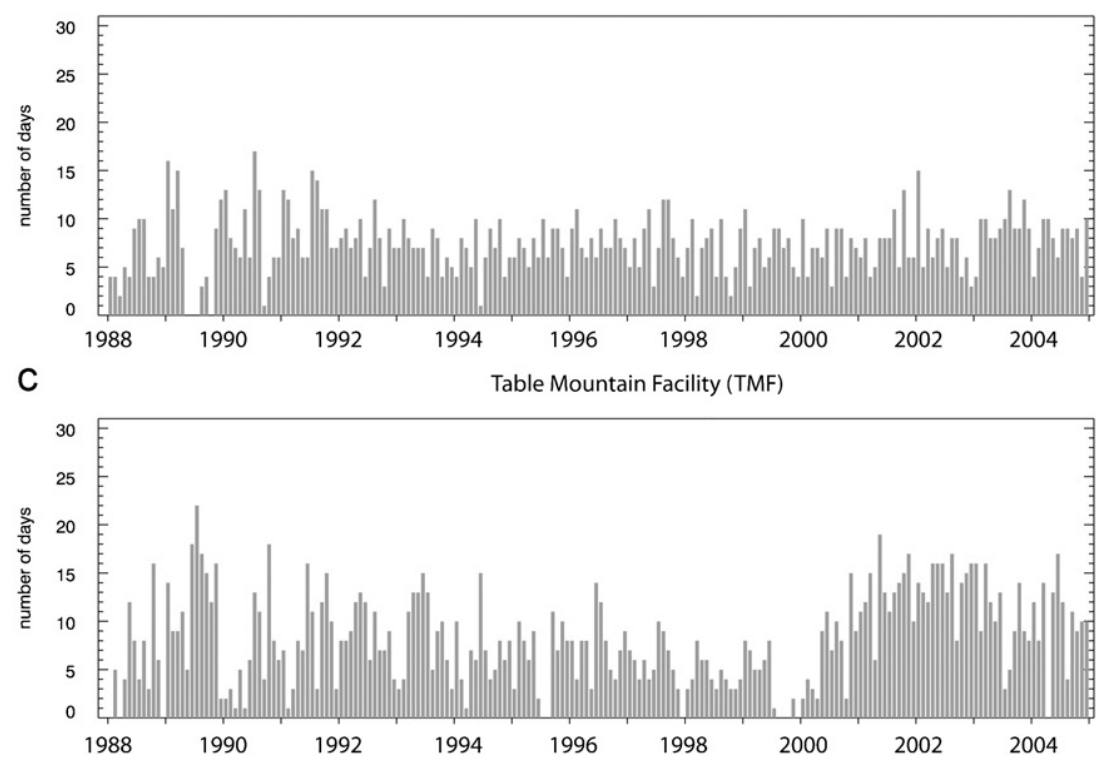

d Mauna Loa Observatory (MLO)
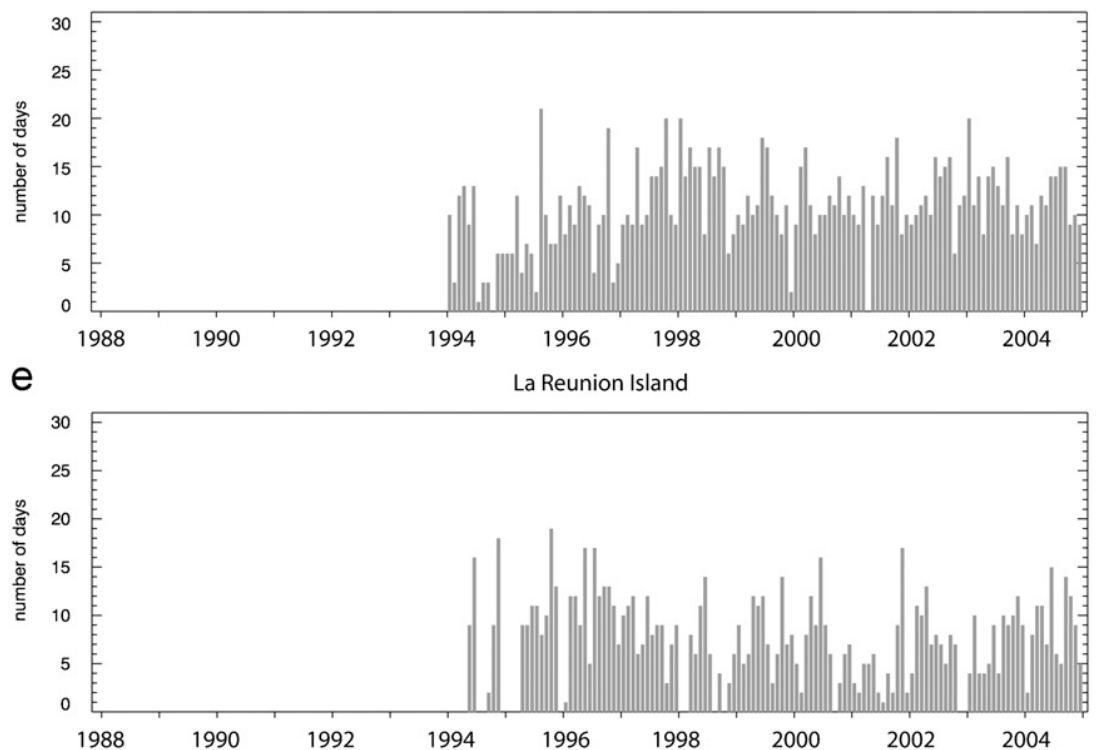

Fig. 1. Time evolution of the monthly number of days of measurements for five lidar sites. (a) Observatory of Haute-Provence, (b) Hohenpeissenberg observatory, (c) Table Mountain facility, (d) Mauna Loa and (e) Réunion island.

Temporal continuity of SSU time series has been investigated by different methods: comparison with rockets, step regression analyses, and comparison of data for adjacent periods, with slightly different results (Gelman et al., 1986). Finger et al. (1993) compared the operationally derived temperatures with collocated rocketsonde observations and found systematic biases of the order of $3-6 \mathrm{~K}$ in the upper stratosphere. Furthermore, these biases change with the introduction of new operational satellites. Finger et al. (1993) provided a set of recommended corrections to the temperature data, which have been used by an NOAA. In spite of the application of the recommended adjustments, the time series of temperature anomalies from the NOAA analyses still exhibit significant discontinuities due to tidal interferences, occurring when the time of the equatorial orbit crossing 
changed between two successive satellites (Keckhut et al., 2001). The first NOAA operational product (Finger et al., 1993) that used rocket measurements for successive adjustments, revealed some discontinuities at the upper stratospheric levels when compared with the Observatory of Haute-Provence (OHP) lidar temperature series (Keckhut et al., 2001).

One additional problem with the continuity of the SSU series arises from the fact that the observed radiances are due to $\mathrm{CO}_{2}$. As $\mathrm{CO}_{2}$ in the atmosphere has been increasing continuously, the weighting functions of the different channels change mainly shifting to higher altitudes. This effect has been already addressed (Brindley et al., 1999), but corrections were recently assessed (Shine et al., 2008) for the last 13 years (corresponding to a 20 ppmv $\mathrm{CO}_{2}$ increase), using a line-by-line radiative transfer code set up initially for an SSU. While both studies give similar results, these last calculations were mainly related to the zonal estimates of the induced long-term drifts of the weighting function associated with $\mathrm{CO}_{2}$ increase. The inferred temperature changes are largest for channel $47 \mathrm{X}$ and vary from $-0.34 \mathrm{~K}$ over the last 13 years at high latitudes, to $-0.65 \mathrm{~K}$ for the tropics. The negative change is due to the negative vertical temperature gradient in the mesosphere. For the 36X channel, temperature changes are smaller because its maximum is close to the stratopause. Conversely, over the last 13 years, channels 26 and 27 exhibit temperature increases of $0.35 \mathrm{~K}$ and from 0.17 to $0.24 \mathrm{~K}$, respectively, quite uniformly with latitude.

\section{Ground-based lidar temperature series}

Until now there were very few ground-based or in-situ measurements available to ensure the continuity and quality of the upper air temperature satellite measurements. The rocket network was used for such a purpose, but launches decreased dramatically after 1980 and there are no continuing long-term measurements (Finger et al., 1993). In a pure molecular atmosphere, temperature profiles can be derived from Rayleigh scattering of a laser beam sent vertically (Hauchecorne and Chanin, 1980) by assuming the atmosphere follows the ideal gas law and is in hydrostatic equilibrium. The temperature profiles obtained from Rayleigh lidar do not require any external calibration. Temperatures are typically measured from 30 to around $80 \mathrm{~km}$, where the atmosphere is not polluted by the presence of aerosols. Temperature profiles can be derived with a mean accuracy better than $1 \mathrm{~K}$ from 30 to $70 \mathrm{~km}$. Above $70 \mathrm{~km}$, the temperature uncertainty increases rapidly with altitude due to photon counting uncertainties and the influence of the tie-on temperature (or pressure) at the top of the profile. Under the framework of the NDACC, several lidars have continuous long-term observations that provide temperature time-series, since the late 1980 s at very different locations (Table 2).

The longest lidar temperature series, since 1979, is from the Observatory of Haute-Provence (OHP) in southern France $\left(43.9^{\circ} \mathrm{N}\right.$, $5.7^{\circ} \mathrm{E}$ ). The configuration of this lidar has been described by Keckhut

Table 2

List of lidar stations used in this study.

\begin{tabular}{lccl}
\hline Station & Latitude & Longitude & $\begin{array}{l}\text { Date of first } \\
\text { operations }\end{array}$ \\
\hline ALOMAR & $69.3^{\circ} \mathrm{N}$ & $16.0^{\circ} \mathrm{E}$ & 1993 \\
Hohenpeissenberg & $47.80^{\circ} \mathrm{N}$ & $11.02^{\circ} \mathrm{E}$ & 1987 \\
Observatory of Haute-Provence & $43.93^{\circ} \mathrm{N}$ & $5.71^{\circ} \mathrm{E}$ & 1979 \\
Table mountain facility & $34.04^{\circ} \mathrm{N}$ & $117.70^{\circ} \mathrm{W}$ & 1988 \\
Hawaii & $19.54^{\circ} \mathrm{N}$ & $155.58^{\circ} \mathrm{W}$ & 1993 \\
La Réunion & $21.80^{\circ} \mathrm{S}$ & $55.5^{\circ} \mathrm{E}$ & 1994 \\
\hline
\end{tabular}

et al. (1993). Temperature trends have been derived in the stratosphere and mesosphere (Hauchecorne et al., 1991). Another continuously operating lidar is located at Hohenpeissenberg $(\mathrm{HOH})$ in Germany $\left(47.8^{\circ} \mathrm{N}, 11.0^{\circ} \mathrm{E}\right) 600 \mathrm{~km}$ north-east of an OHP. This Differential Absorption Lidar (DIAL) system has been in operation since the end of 1987 and was designed for ozone and temperature profile measurements. It uses a setup very similar to that described by Werner et al. (1983) and Steinbrecht et al. (1989). The Jet Propulsion Laboratory (JPL) Table Mountain Facility (TMF) in California $\left(34.4^{\circ} \mathrm{N}, 117.7^{\circ} \mathrm{W}\right)$ also operates a DIAL system measuring both ozone and temperature that has been in routine operation since 1988 (McDermid et al., 1990; Leblanc et al., 1998). The JPL team also operates a DIAL system at Mauna Loa Observatory (MLO), Hawaii $\left(19.5^{\circ} \mathrm{N}, 155.6^{\circ} \mathrm{W}\right)$ since 1993. In the southern hemisphere, the Laboratoire Atmosphères, Milieux, Observations Spatiales (LATMOS) and the University of La Réunion (Laboratoire de l'Atmosphere et des Cyclones (LACy)) implemented a Rayleigh lidar for temperature measurements at La Réunion Island $\left(21.8^{\circ} \mathrm{S}, 55.5^{\circ} \mathrm{W}\right)$ in 1993. This instrument is very similar to the OHP system and uses the same retrieval algorithm. The Arctic Lidar Observatory for Middle Atmosphere Research (ALOMAR) described by Thrane and von Zahn (1995) was established in 1993 and is located on the North-Norwegian island of Andoya $\left(69.3^{\circ} \mathrm{N}, 16.0^{\circ} \mathrm{E}\right)$. This lidar is very powerful, but temperature measurements during summer are less numerous than winter and are noisier, due to the influence of sunlight during this period of long lasting daytime period. ALOMAR data set does not belong to the NDACC and is not publicly available, thus do not provide the same level of documentation as the other NDACC stations. However, we include these data in the present work to evaluate the potential contribution of such a high latitude lidar.

The lidar series from both the Hohenpeissenberg Observatory and the Observatory of Haute Provence are very valuable because these stations are close together and can provide a cross-validated ground-based reference with a greater consistency. Table Mountain Facility is also located at mid-latitudes, but further south and $120^{\circ}$ in longitude apart from the previous two stations. The two other locations included in this study (La Réunion and Hawaii) are located near the tropics in each hemisphere where the daily variability is the smallest, but the series have began more recently than mid-latitude stations.

The atmosphere monitoring requires homogeneous series with operational protocols and instrumental setups unchanged. This is virtually impossible with lidar for many reasons. While the lidars require clear nights to operate, routine measurements rely on dedicated technicians and maintenance resources. The data archive (http://www.ndacc.org) for the three mid-latitude stations reveals a seasonal cycle and indicates that the number of measurements can vary significantly with time (Fig. 1 ). The three longest series provide around 5-10 profiles per month: from 1994 to 2000 , the measurement rate has doubled at an OHP (Fig. 1a), $\mathrm{HOH}$ provides a regular rate (Fig. $1 \mathrm{~b}$ ), while TMF provides a very variable rate (Fig. 1c) with few profiles around 1998-2000 and a small period of interruptions and larger rate of around 15 profiles per month in the 2001-2003 period.

The designs of the lidars involved in the NDACC differ slightly. While these differences in theory do not cause bias on the temperature retrieval, the derivation methodologies could induce differences in the top of the profiles at varying heights in the mesosphere (Singh et al., 1996; Leblanc et al., 1998). The main limitation is due to the statistical noise. These errors increase rapidly with altitudes as soon as the number of photons collected is similar to the sky background. This condition directly determines the altitude range of the profiles. The estimated errors at $50 \mathrm{~km}$ (Fig. 2) allow monitoring lidars capability changes with time. OHP and TMF systems present an error ranging $0.5-1 \mathrm{~K}$ 

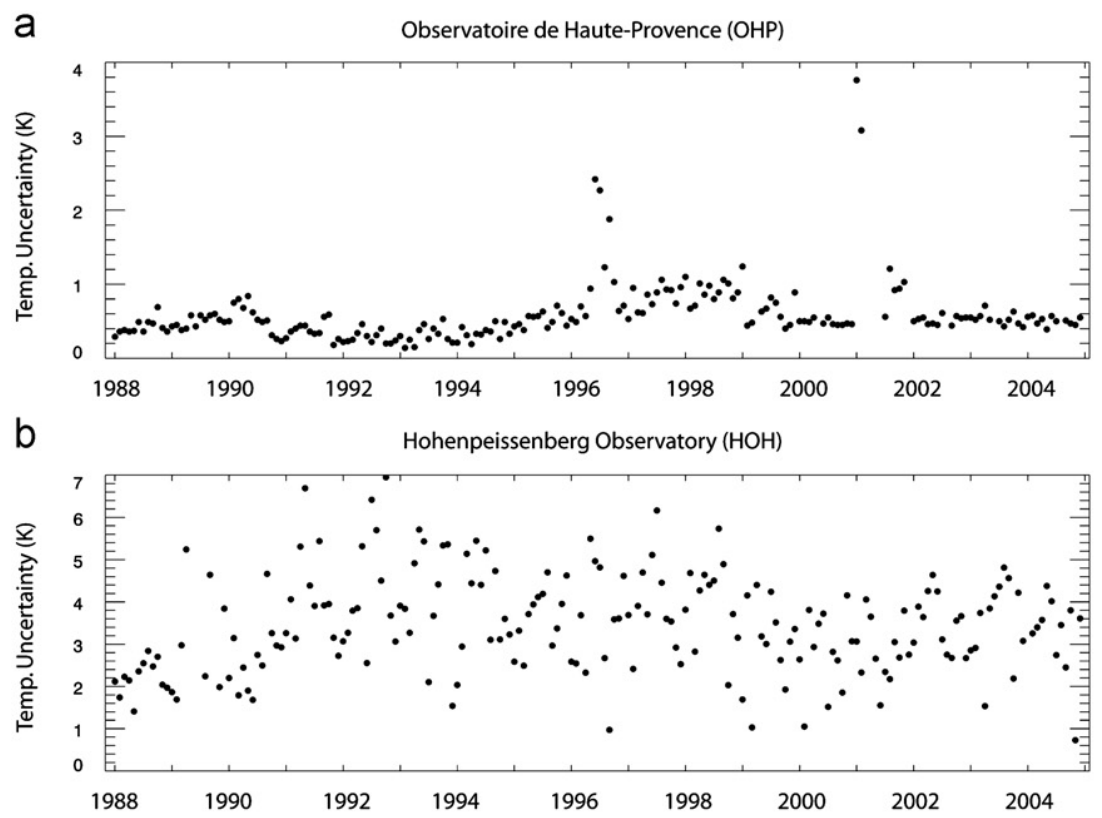

C

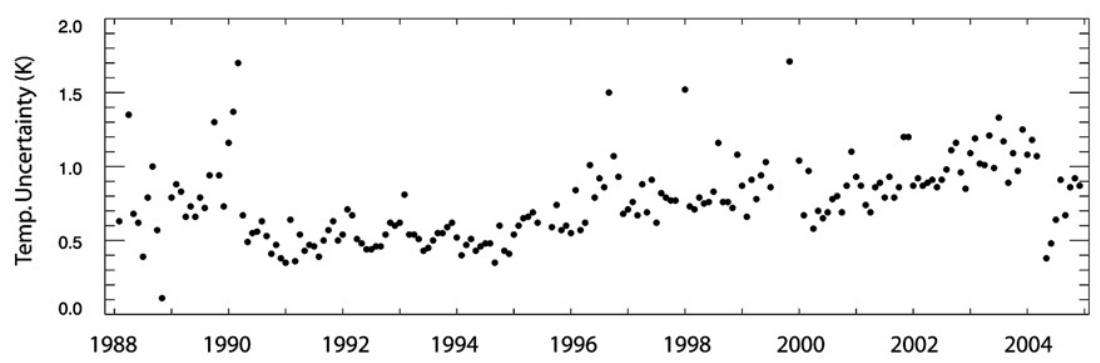

d

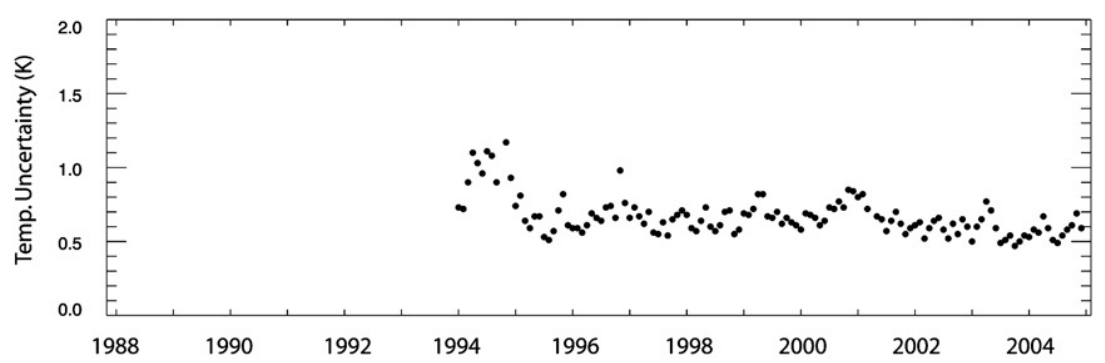

e

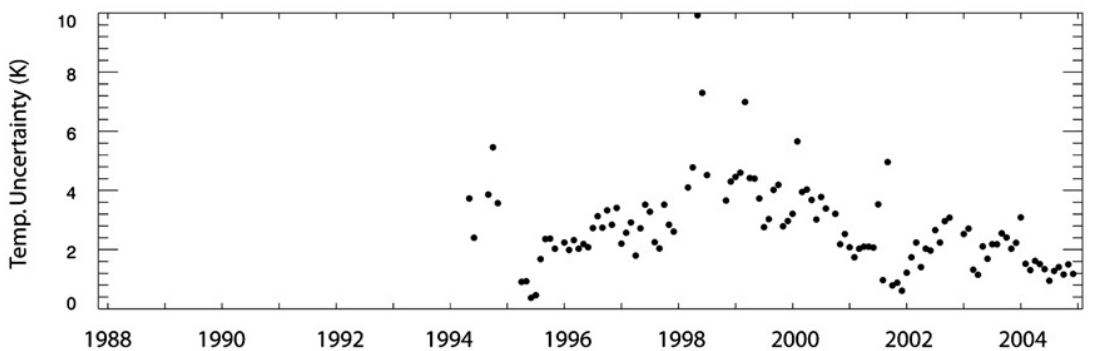

Fig. 2. Time evolution of monthly mean measurement errors at $50 \mathrm{~km}$ for five lidar sites. (a) Observatory of Haute-Provence, (b) Hohenpeissenberg observatory, (c) Table Mountain facility, (d) Mauna Loa and (e) Réunion island.

(Fig. 2a,c) with periods of slow increase associated with laser degradations. The initial TMF data obtained in 1988 correspond to the preliminary lidar setup, and are shown here for illustrative purposes only. $\mathrm{HOH}$ system having smaller capabilities (laser power and telescope surface area) reveals larger statistical errors up to $7 \mathrm{~K}$ (Fig. 2b).
Because of the weather, the duration of the integration time and the starting time of the measurements varies from day to day and differently at each station. Consequently, the atmospheric tides (Keckhut et al., 1996; Leblanc et al., 1999a, 1999b; Morel et al., 2002), associated with changes of the portion of night when measurements are performed, induce temperature anomalies 
that vary from night to night. Tidal amplitude of $\pm 2 \mathrm{~K}$ and a maximum at 17:00 solar time, corresponding to the mean tidal characteristic observed around $50 \mathrm{~km}$ (where the amplitude in the stratosphere is largest) are used to estimate the additional temperature anomaly superimposed on measurements (Fig. 3) as done by Wild et al. (1995) and Keckhut et al. (2001). This statistical model does neither include semi-diurnal tides, nor accounts for latitudinal dependency of amplitudes and phases. Despite these shortcomings, the model provides a rough estimate of the uncertainty associated with tidal effects. It is worthwhile to point that at $50 \mathrm{~km}$ and above gravity waves also induce large variability in the observed temperatures. Both European series (OHP and $\mathrm{HOH})$ have shown larger variability due to tides compared to the TMF site. One can note that OHP series (Fig. 3a)

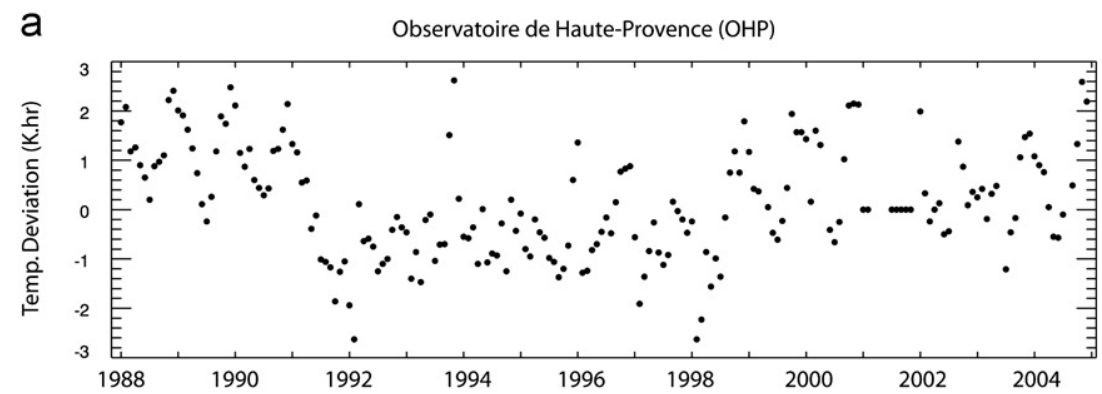

b

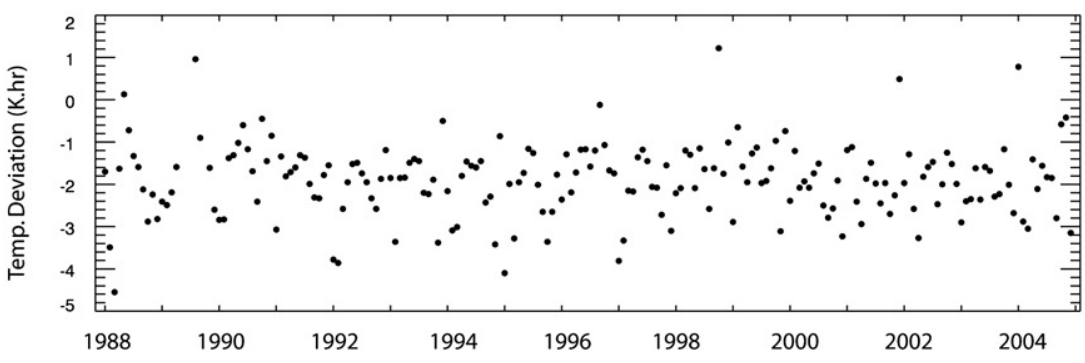

C

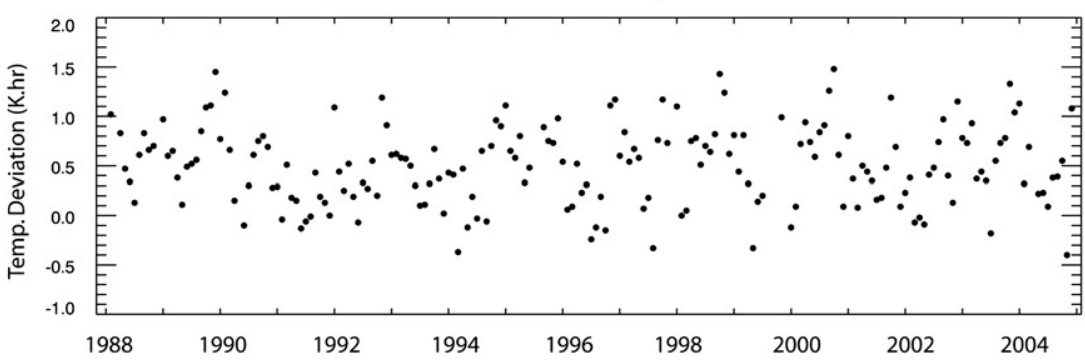

d

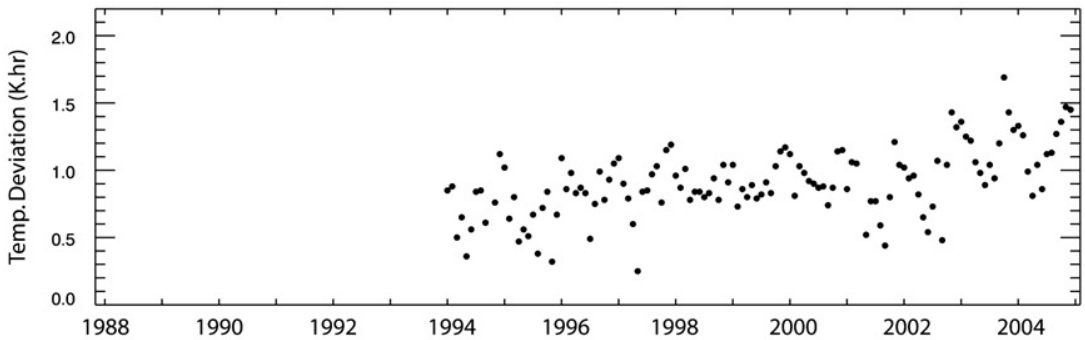

e

La Reunion Island

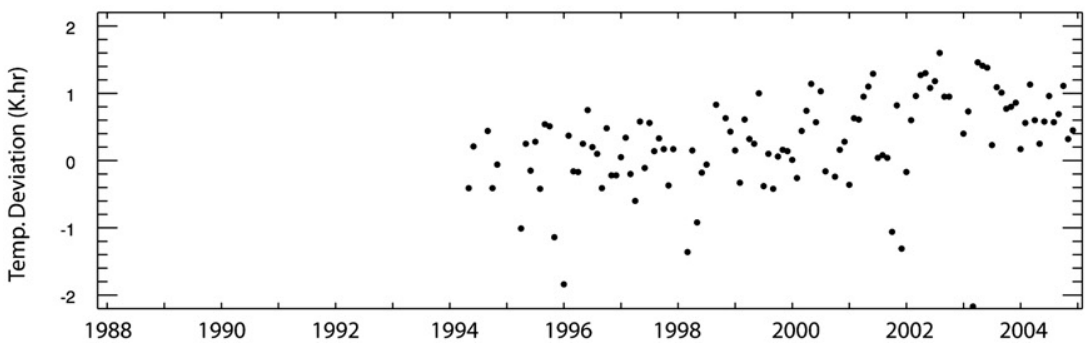

Fig. 3. Time evolution of the simulated monthly temperature anomalies induced by atmospheric tides estimated from tidal model characteristics at 50 km (Keckhut et al. 1996) km for the five lidar sites. (a) Observatory of Haute-Provence, (b) Hohenpeissenberg observatory, (c) Table Mountain facility, (d) Mauna Loa and (e) Réunion island. 
could include a systematic mean difference of $2 \mathrm{~K}$ between 1991 and 1999. However, this would have induced a minor additional trend as already reported (Keckhut et al., 2001). In the future, these estimates can be improved with appropriate observations with lidar and the Sounding of the Atmosphere using Broadband Emission Radiometry (SABER) mission (Zhang et al., 2006).

Synthetic lidar data series have been produced to fit the SSU radiances by averaging each individual lidar profile (obtained generally with a vertical resolution from 75 to $300 \mathrm{~m}$ ) with the vertical weighting functions of each of the SSU channels. For comparisons with lidar, only channels 26, 36X, 27, and 47X, exhibiting the maximum of their weighting functions above the lower Rayleigh lidar altitude range (around $25-30 \mathrm{~km}$ ), have been investigated. The maxima of the weighting functions of these channels (Table 1 ) are located at the pressure levels of $4 \mathrm{hPa}$ (38 km), $2.5 \mathrm{hPa}(44 \mathrm{~km}), 2 \mathrm{hPa}(45 \mathrm{~km})$, and $1 \mathrm{hPa}(50 \mathrm{~km})$. However, as some stations cannot provide temperature below $30 \mathrm{~km}$, the weighting functions have been forced to 0 below $30 \mathrm{~km}$ and SSU weighting functions have been renormalized to take into account the missing part of the temperature profiles below $30 \mathrm{~km}$. The missing portion is small and the temperature changes below the few kilometers under $30 \mathrm{~km}$ should have a limited contribution since only the large scale, long-term changes have been investigated. The temperature profile below $30 \mathrm{~km}$ contributes around $20 \%$ of the Channel 26 radiance and is the worst case among the four channels selected. For channel 27 , less than $10 \%$ of the radiance comes from altitudes below $30 \mathrm{~km}$, while the synthetic SSU channels (36X and 47X) have negligible radiance contributions from altitudes below $30 \mathrm{~km}$. Since SSU zonal temperatures are available in $10^{\circ}$ latitude bands, an interpolation has been performed to fit the lidar station latitudes. In the remaining of the manuscript, "lidar data series" refer to the SSU-fitted, synthetic temperature series.

\section{Lidar-SSU comparisons}

\subsection{Decadal evolution}

In a first step for lidar-SSU comparisons, lidar data have been vertically averaged to fit the SSU weighting functions as described in the former section. For example, TMF lidar profiles have been extended downward with a Raman channel and compared with SSU climatology (Fig. 4). The agreement for near nadir viewing channels (26 and 27) is quite good however for combined channels (36X and 47X) a clear bias is seen. The difference can be due to time differences and tidal effects however the fact that such bias do not appear for channel 27 does not support such hypothesis. When the weighting functions are shifted, respectively, by 2.5 and $5 \mathrm{~km}$ for channels 36X and 47X, good agreement between annual climatologies is obtained, thus suggesting errors in the weighting functions.

In the following, only temperature temporal anomalies have been considered and have been calculated by removing annual and semi-annual means that are sinusoidal-like functions. The resulting lidar temperature series have then been smoothed with a running mean of five months for all stations, and are presented in Fig. 5 for channel 47X. The five month running mean was performed as a good compromise to reduce the noise and to provide inter-annual anomalies comparable with SSU data, which are zonally smoothed. The temperature series show inter-annual anomalies that can be associated with the Quasi-Biennal-Oscillation (QBO), El Niño-Southern Oscillation (ENSO), volcanic aerosols loading, and with the 11-year solar cycle (Li et al., 2008). Cooling trends are clear at all levels, but are the largest for the upper stratospheric levels corresponding to channels $27 \mathrm{X}$ or $47 \mathrm{X}$. Because of the long tails of the weighting functions, these levels also match well with the range of Rayleigh lidars. The SSU series reveal a clear flattening at all latitude bands after mid 1990s.

The comparison between SSU and lidars at the three midlatitude sites reveals a similar temporal behavior, showing a continuous cooling in the early 1990s, followed by a null-trend (slight warming) after 1994 (Fig. 5a,b). However, some discrepancies between SSU and lidar series can be reported. For the highest levels (channels 27X and 47X), the $\mathrm{HOH}$ lidar shows a large positive anomaly in 1998/1999 with the largest differences to an SSU of around $3.5 \mathrm{~K}$ for channel $47 \mathrm{X}$ that is not seen by the OHP lidar. The TMF lidar reveals a larger trend than the one reported by an SSU, which can be described as either a continuous drift or sudden changes in 1995-1996, and warmer lidar temperature at the beginning of the series (1988-1989). These differences can be
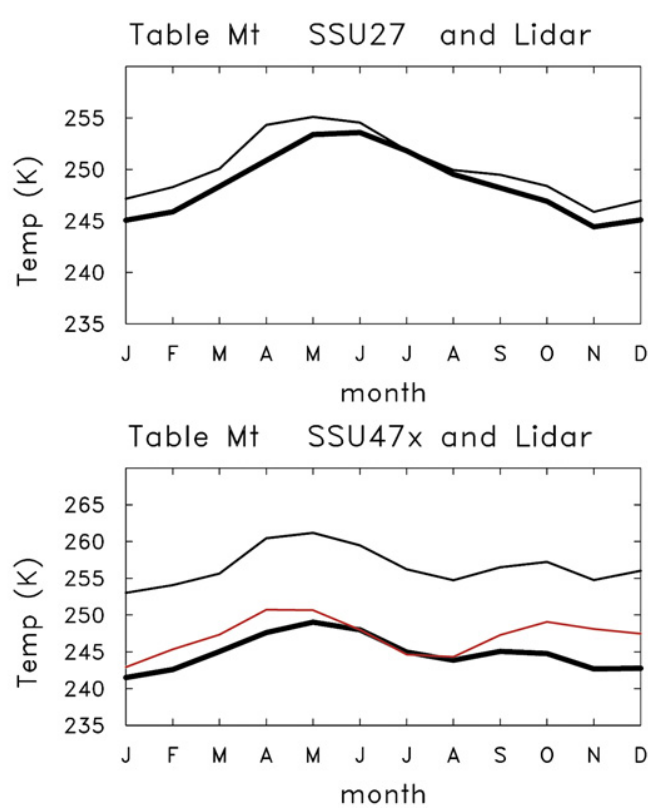

Fig. 4. Comparison of the temperature climatology from the four SSU channels (dark line-26X, 27X, 36X, and 47X) and TMF lidar vertically weighted with SSU weighting functions (thin line). For channels 36X and 47X, red lines correspond to lidar synthetic data using weighting functions vertically shifted upwards by 2.5 and 5 km, respectively. (For interpretation of the references to color in this figure legend, the reader is referred to the web version of this article.) 

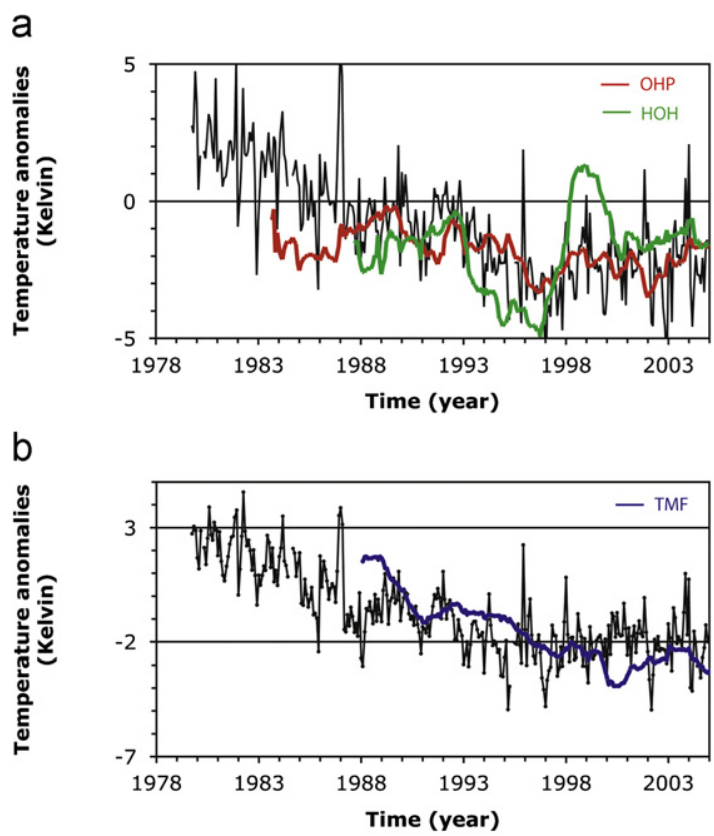

d
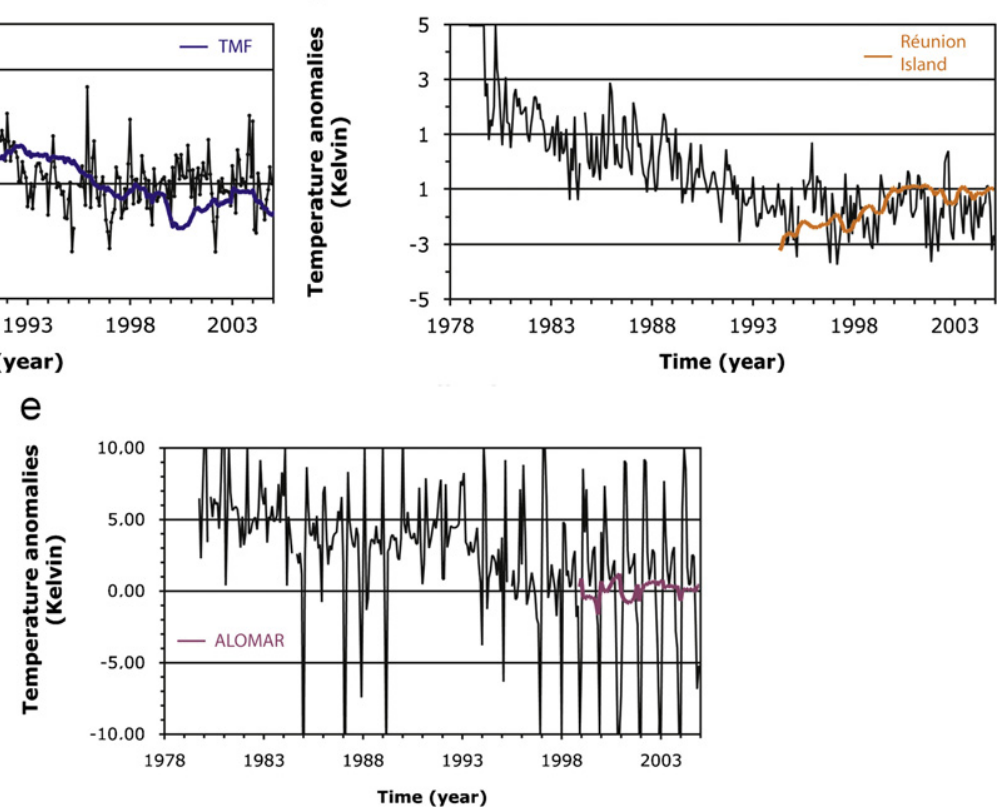

Fig. 5. Zonal monthly mean temperatures anomalies derived from SSU channel 47X (black line) compared to corresponding monthly mean of weighted lidar profiles at the six sites: (a) OHP (red) and Hohenpeissenberg (green), (b) Table Mountain (dark blue), (c) Mauna Loa (light blue), (d) La Réunion (orange), and (e) Alomar (purple). (For interpretation of the references to color in this figure legend, the reader is referred to the web version of this article.)

seen at all levels, but are the largest for the upper SSU levels (27X and 47X). The SSU temperature series show a cooling up to 1994 and no further cooling afterwards (Fig. 5). The length of both tropical lidar series is too short to report on the transition between the previous decadal cooling and the actual steady phases (Fig. 5c,d). However, the inter-annual changes during this second period are quite similar on SSU and tropical lidar series. At the highest latitudes $\left(70^{\circ} \mathrm{N}\right)$, the SSU temperature series exhibit large anomalies due to the large winter inter-annual variability (Fig. 5e). However, the linear trend and the flattening starting in 1994 are still visible and in agreement with ALOMAR lidar $\left(69^{\circ} \mathrm{N}\right)$ showing a stable long-term temperature evolution. The effect of the 11-year, the solar cycle, is also visible on the SSU series. Good agreement with lidar has been already reported (Keckhut et al., 2005). Zonal SSU analysis is not appropriate to monitor high latitude changes in the mid-upper stratosphere and is also not adequate to monitor the high latitude temperature changes. The use of more stations (at least three) would be required for such investigations.

\subsection{Investigations on causes of discrepancy at mid-latitude}

One possible way to further quantify the data consistency can be through the analysis of lidar-SSU monthly differences (notice we use the "SSU-weighed" lidar profile to perform the calculations, see beginning of the previous subsection). Because large scale inter-annual changes are supposed to be recorded similarly from ground-based and space instruments and independently from the viewing geometry, these differences can be considered to be caused solely by instrumental changes or slow drifts of the mean in either series. The trends calculated on differences between lidar and SSU series will be referred hereafter as "differential residual trends".

Fig. 6 shows differences between monthly mean lidar and SSU temperatures for the lowest altitude (channel 26) for the midlatitude stations. The OHP temperature lidar data are warmer than SSU up to 1987 (Fig. 6a), probably due to the effect of early lidar misalignment problems already reported (Keckhut et al., 2001). For this reason, differential residual trends over the full period are equal to $-0.9 \pm 0.4 \mathrm{~K} /$ decade. For Hohenpeissenberg, the differential residual trend over the period 1994-2004 exhibits a reverse sign with an amplitude of $+0.7 \pm 1.2 \mathrm{~K} /$ decade, closer to the expected SSU drift of $0.34 \mathrm{~K}$ over 13 years estimated by Shine et al. (2008). Large positive bias can be observed for TMF site at the beginning of the series in 1988. When initial data from 1988 are removed residual trends of more than $1 \mathrm{~K} /$ decade are still observed. For the intermediate SSU channels (36X), OHP and Hohenpeissenberg temperature series show non-significant differential residual trends with respective amplitudes of $0.2 \pm 0.4 \mathrm{~K} /$ decade and $0.1 \pm 0.4$, in agreement with the expected small drift due to the weighting function drifts (not shown).

Differential residual trends in the upper stratosphere (channel 47X) over the period 1994-2004 exhibit values as large as $0.6 \pm 0.3$ and $1.7 \pm 0.6 \mathrm{~K}$, respectively, for $\mathrm{OHP}$ and $\mathrm{HOH}$ series (Fig. 7). For the 
a

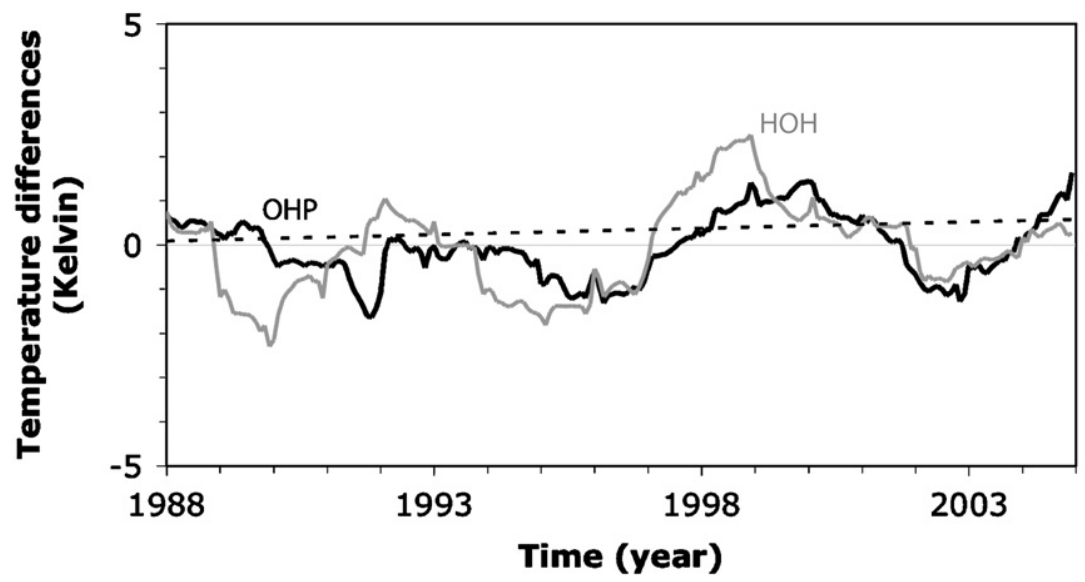

b

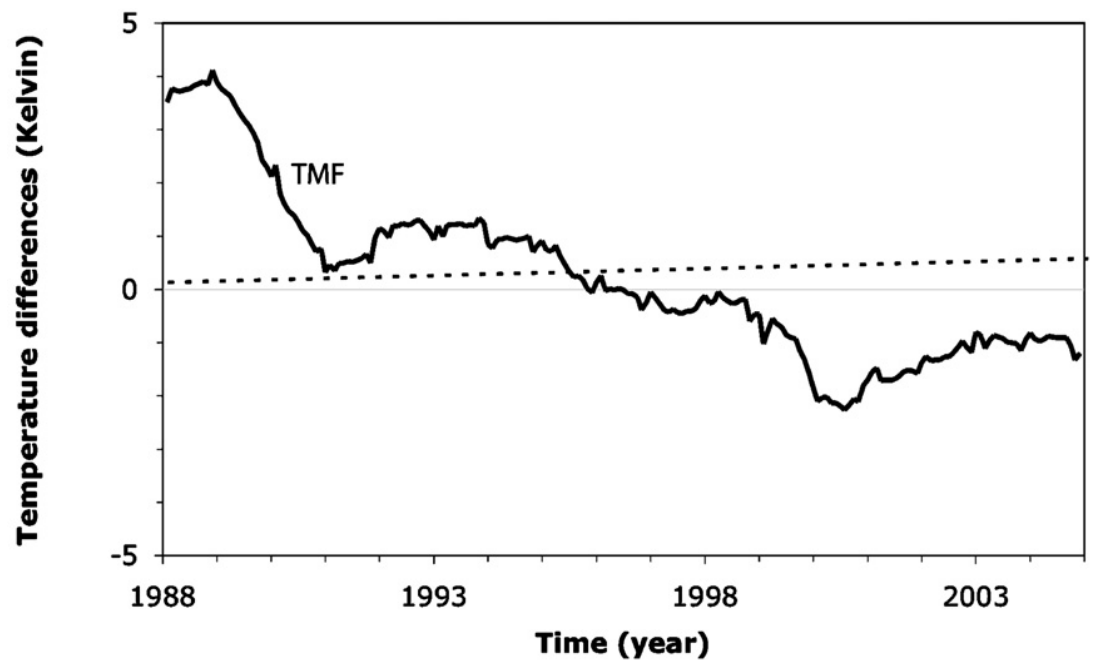

Fig. 6. Temperature differences between zonal monthly mean temperatures derived from SSU channel 26 and monthly means of weighted lidar profiles (Tlidar-TSSU) at mid-latitude sites: (a) OHP-black line and Hohenpeisenberg-gray line and (b) Table Mountain. In both panels, the induced trends due to weighting function changes are represented by dash lines.

French site (OHP), the differential residual trend between lidar and SSU is of the same order as the $\mathrm{SSU}-\mathrm{CO}_{2}$ bias (which was estimated to be the largest for the $47 \mathrm{X}$ channel), but the differential residual trend is double for the German lidar. Figs. 5a and 7a show obvious differences between temperatures at these two fairly close lidar stations ( $\mathrm{HOH}$ and OHP). It is tempting to attribute such differences to instrumental changes or drifts. Because this anomaly was not detected at lower levels (Fig. 6a) and lasted for few years, it could be explained a priori by an increase of the lidar noise (Fig. 2b). The HOH lidar is less powerful (given by the product of collector area and laser power) than the OHP instrument and the upper part of those profiles is noisier (Fig. 2b). Since SSU weighting functions have a wide vertical extension, larger biases in the upper part of the lidar profile could have induced larger noise into the synthetic lidar signal created for SSU comparisons. However, the error has not changed during this period (Fig. 2b).

In the upper stratosphere, the continuity could depend on tidal effects. For OHP series, we would have expected some tidalinduced bias between 1991 and 1998 (Fig. 3a), but such a bias is not evident neither through the correlation of temperature anomalies (Fig. 5a) nor on temperature differences with an SSU (Fig. 6a). Tidal effects estimated in Section 2 on $\mathrm{HOH}$ lidar series (Fig. 3b) cannot explain such observed anomaly as the estimated tidal anomaly remains nearly constant. Some bias can exist, mainly during winter, if stratospheric warming were not randomly sampled during this period. However, under-sampling effects could not explain such an anomaly as the measurement rate of $\mathrm{HOH}$ remains nearly constant (Fig. 3b). The atmosphere is not zonally symmetric, and even two fairly close stations can experience different geophysical variations. Differences can be enhanced by distinct sampling dates.

Fig. 8 shows the vertical profile of the linear trend of temperature differences between $\mathrm{HOH}$ and OHP as measured by the two lidars and as reported by the operational meteorological analyses from the US National Center for Environmental Prediction (NCEP). The NCEP analyses are based on operational SSU temperatures, and below $30 \mathrm{~km}$ also on operational meteorological radio-soundings. The continuity is not perfectly insured on the long-term; however, the changes in the operational analyses have much less effects on the $\mathrm{HOH}-\mathrm{OHP}$ temperature difference than on absolute temperatures. Over the 1992 to 2006 period, the NCEP data clearly show a trend towards colder temperatures at $\mathrm{HOH}$ (compared to OHP) throughout most of the troposphere, as well as in the $20-30 \mathrm{~km}$ region. In the $35-55 \mathrm{~km}$ region, as well as in the lowermost stratosphere, the NCEP data show a clear trend towards higher temperatures at $\mathrm{HOH}$. The NCEP trend between 35 and $50 \mathrm{~km}$ is independently confirmed by the lidar data, which 

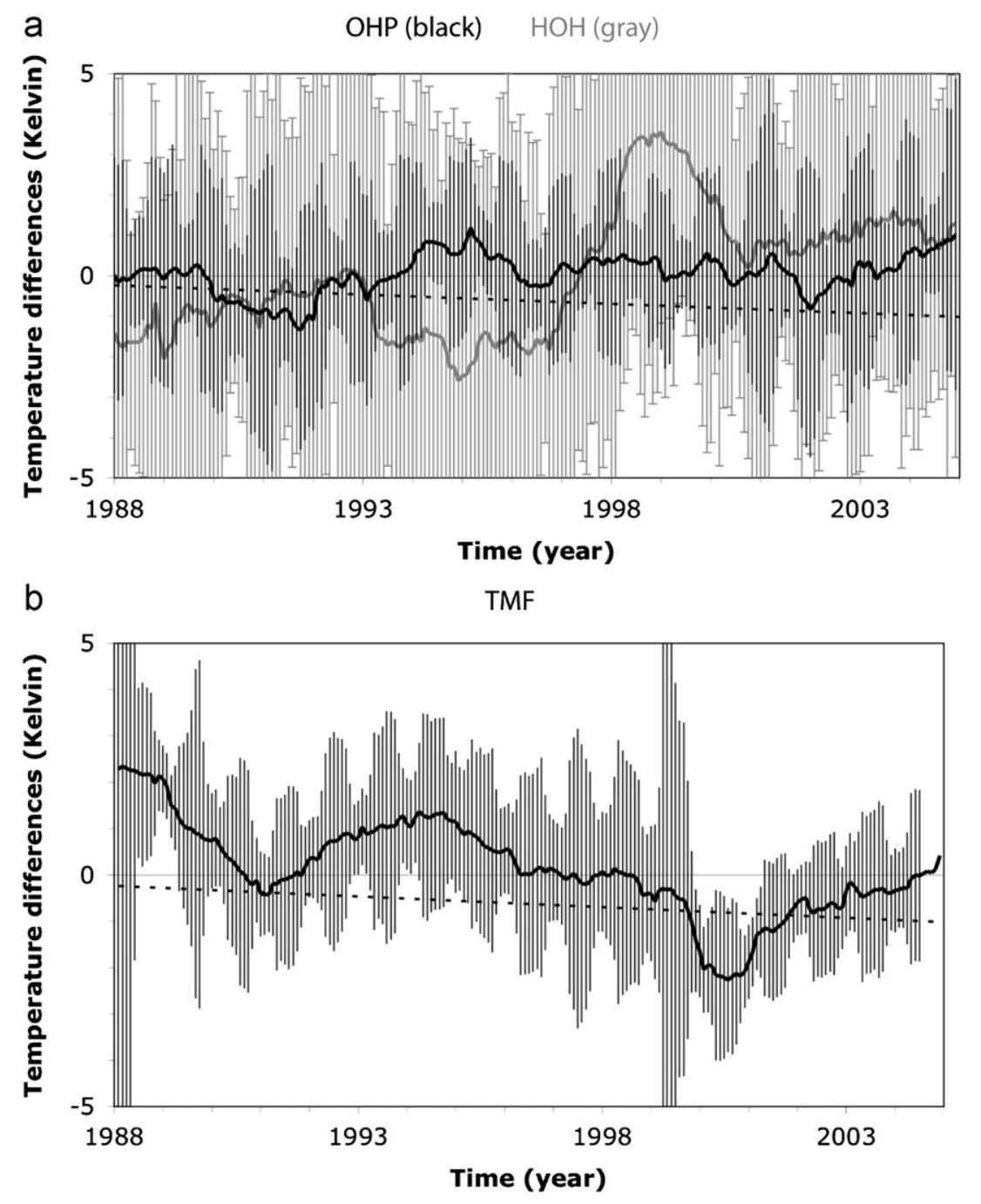

Fig. 7. Temperature differences between zonal monthly mean temperatures derived from SSU channel 47X and five month running means of weighted lidar profiles (Tlidar-TSSU) at mid-latitude sites: (a) OHP-black line and Hohenpeissenberg-gray line, and (b) Table Mountain. In both panels, the induced trends due to weighting function changes are represented by dash lines. Gray shaded areas represent the lidar uncertainties (see text).

show an even more pronounced trend in the temperature difference between the two stations. Although $\mathrm{HOH}$ and OHP are only about $700 \mathrm{~km}$ apart, Fig. 8 quite clearly shows that temperature trends at two stations can differ as much as $2 \mathrm{~K}$ per decade over a 15 year period. A substantial part of the drift seen between temperatures at $\mathrm{HOH}$ and at OHP is not caused by the instruments and seems to be actually a true change in the atmosphere. Similar drifts can be expected for other locations and daily temperature comparisons between both locations should be further investigated. For example, when examining the differences between $\mathrm{HOH}$ and OHP temperature series and the corresponding NCEP monthly mean temperature differences (both with annual cycle removed) close to these stations, for altitudes between 30 and $50 \mathrm{~km}$, results show that correlations between lidar- and NCEP-based $\mathrm{HOH}-\mathrm{OHP}$ temperature differences increase from 0.2 to 0.3 when using all available nights to form NCEP monthly mean temperatures, to $0.4-0.8$ when monthly means are based only on nights, where both lidars had measurements. For comparison, Funatsu et al. (2008) reported an increase in correlation when comparing lidar and AMSU temperature (minus long-term mean) at an OHP for the period 2001-2007 using lidar measurement nights and all nights to compute monthly means: correlation increased up to $\sim 15 \%$ when using only AMSU data for overpasses coincident with OHP measurement dates, from $0.65-0.81$ to $0.76-0.90$, depending on height and channel. Besides, the range of NCEP-based HOH-OHP differences is about half of that "seen" by lidars differences (not shown), and may be explained by the inherent vertical and horizontal smoothing of NCEP data, and also because NCEP temperature variations seem to be generally dampened in the upper layers (e.g., Steinbrecht et al., 2009). These results indicate that differences between the two lidar sites have true geophysical origin. An analysis of these differences using AMSU and lidars is further discussed by Funatsu et al. (accepted for publication).

Differential residual trends above TMF exhibit a reverse sign compared to OHP and $\mathrm{HOH}$. The differential residual trends during the period 1994-2004 are somewhat reduced compared to the estimates using the whole period (1988-2004), because of the warmer temperature observed in 1988. However, the differential residual cooling between TMF lidar and SSU is still large and ranges $1-2 \mathrm{~K} /$ decade. The differential residual cooling between TMF lidar and SSU is around $1 \mathrm{~K} /$ decade for channel 47X. Half of the drift can be due to $\mathrm{CO}_{2}$ induced SSU drift (Fig. 7b); in this case, the simulated tidal anomalies show that such effect can be responsible for another part of the observed differential residual trend. Continuous changes of the simulated tidal anomalies can be observed (Fig. 3c) on the lidar series as well as a strong discontinuity on the beginning of the series. The different sign at 


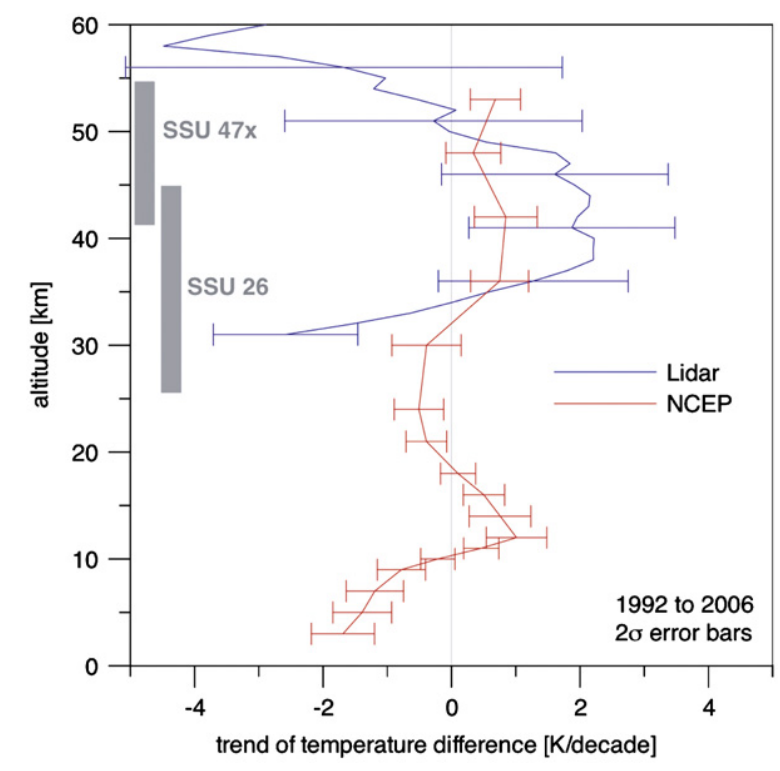

Fig. 8. Linear trend of differences between monthly mean temperature above Hohenpeissenberg and OHP (T(HOH)-T(OHP)), for the period 1992-2006, based on the monthly means of all available lidar temperature measurements at the two stations (blue line above $30 \mathrm{~km}$ ), and on monthly means of the NCEP operational meteorological analyses (red line from ground to $55 \mathrm{~km}$ ). The gray bars show the approximate altitude range (half width) of the SSU channel weighting functions. (For interpretation of the references to color in this figure legend, the reader is referred to the web version of this article.)

$\mathrm{HOH} / \mathrm{OHP}$ and TMF for residual trends could be due to SSU tidal effects similar to the one raised on NCEP data (Keckhut et al., 1996). The confidence in the continuity of the SSU series was unclear, because the change of the observed trend rate in the SSU data series appears when NOAA 14 data were introduced. The orbit crossing time of the NOAA 14 has drifted from 14:00 local time to 21:00 (see Fig. 2 in Randel et al., 2009). If tidal changes exhibit a maximum around 17:00 solar time (as assumed in Section 2 for lidar tidal anomaly estimates), a small-induced trend will be expected. However, the crossing time between NOAA 11 and NOAA 14 consists of a sudden change from 18:00 to $14: 00$ local time, corresponding to temperature tidal changes of around $1-2 \mathrm{~K}$. Alternative adjustments of NOAA 11 and NOAA 14 series would have had a very large impact on the agreement between SSU and lidar series at mid-latitude. A drift of $1 \mathrm{~K}$ would have improved the agreement with the TMF lidar series, while OHP lidar series would have remained in good agreement with an SSU. The investigations using the Advanced Microwave Sounding Unit (AMSU) satellite data series have shown that the sampling could have a significant effect on trend estimates (Funatsu et al., 2008). While the lidar measurement rate is quite variable, it is difficult to draw any final conclusion. Only the period in 2000 exhibits very few measurements (Fig. 1c) that can explain the observed anomaly (Fig. 7b). However, similar behaviors on the time discontinuities are also observed for channels associated with lower altitude levels that correspond to altitudes, where tidal effects are smaller (Fig. 6b). As the largest change occurs around 1990 and 2000 during a limited period, these abrupt changes contribute to significant differential residual trends. Differences can also be attributed to dynamic patterns through a non-zonal planetary wave change (Charlton and Polvani, 2007). Because California is shifted in longitude and is southern in latitude compared to an OHP, it is also possible that atmospheric dynamical changes are differently sampled compared to those seen above Europe, while both European stations correspond frequently to different equivalent latitudes (Nash et al., 1996). These potential horizontal differences are not taken into account through zonal means.
Error bars on the monthly mean temperature estimates (Fig. 7) are estimated from the quadratic sum of the random lidar uncertainties and the sampling effect. Sampling error has been estimated from the climatologic daily variability (derived from lidar data) and the number of measurements per month. When these error bars are considered (Fig. 7a) no significant differences can be reported between SSU and either OHP or HOH sites. For TMF, the temperature series show significant positive differences between SSU and lidar in the mid 1990s and a negative bias observed during the year 2000.

\subsection{Comparisons over the tropics}

While the variability is smaller over the tropical sites, temperature series show small but significant differential residual trends, equal to $0.80 \pm 0.3 \mathrm{~K} /$ decade for an MLO and $1.2 \pm 0.5 \mathrm{~K} /$ decade for La Réunion Island in comparison with the 47X channel (Fig. 7). Those are very different over the 13 years, and are in the opposite directions. However, the temporal evolution (Fig. 5c,d) is similar to that of the SSU series particularly the relative warming reported during the period 1998-2000.

At lower levels, anomalies look like inter-annual oscillations rather than stepwise changes (Fig. 9). Inter-annual anomalies range between $\pm 1 \mathrm{~K}$ for an MLO to $\pm 2 \mathrm{~K}$ for La Réunion. These changes are not in phase and could not be attributed to adjustment of two successive SSU instruments. It is not obvious to attribute these oscillations to lidars discontinuities, because the oscillation bias does not exist anymore at higher altitudes (channel 47X; not shown). These features could be rather due to the non-zonal nature of $\mathrm{QBO}$ signatures or other dynamical features like an ENSO. Again the zonal nature of the SSU series could probably explain why such features were somewhat smoother compared to local measurements.

\subsection{Conclusions about the continuity of lidar series}

From the comparisons between lidar and SSU series, some conclusions can be drawn about the continuities of the lidar series. Some differences with an SSU can be attributed to the changes of the SSU weighting functions, but remains on the range 0.1-0.6 K/decade; however, larger differential residual trends have been observed. In several cases, the zonal nature of the SSU product probably explain some discrepancies with measurements conducted from local stations, mainly in the mid-stratosphere over tropics and at mid-latitude for sites located over Europe and the American continents, where atmospheric dynamics is known to induce large differences. Other sources of discrepancy are probably related to some specific lidar instrumental causes or their time evolutions. The lidar capabilities (laser power and receiver area) define the altitude range and instrumental noise; the projection of lidar synthetic data with satellite large vertical weighting functions could induce spurious bias. In addition, sampling effects can affect comparisons for series based on monthly means of available data since lidar operations depend on weather and institute capabilities and give very variable samples from site to site and also with time. These temporal and horizontal sampling effects were clearly demonstrated by Funatsu et al. (2008).

To insure a more reliable temperature trend estimate with lidar series, useful auxiliary information on data condition can be found on individual data files archived in the NDACC database (http://www.ndacc.org). It consists on evolutions of the measurement occurrence, the mean estimated random lidar error and tidal estimates (due to the integration period). 

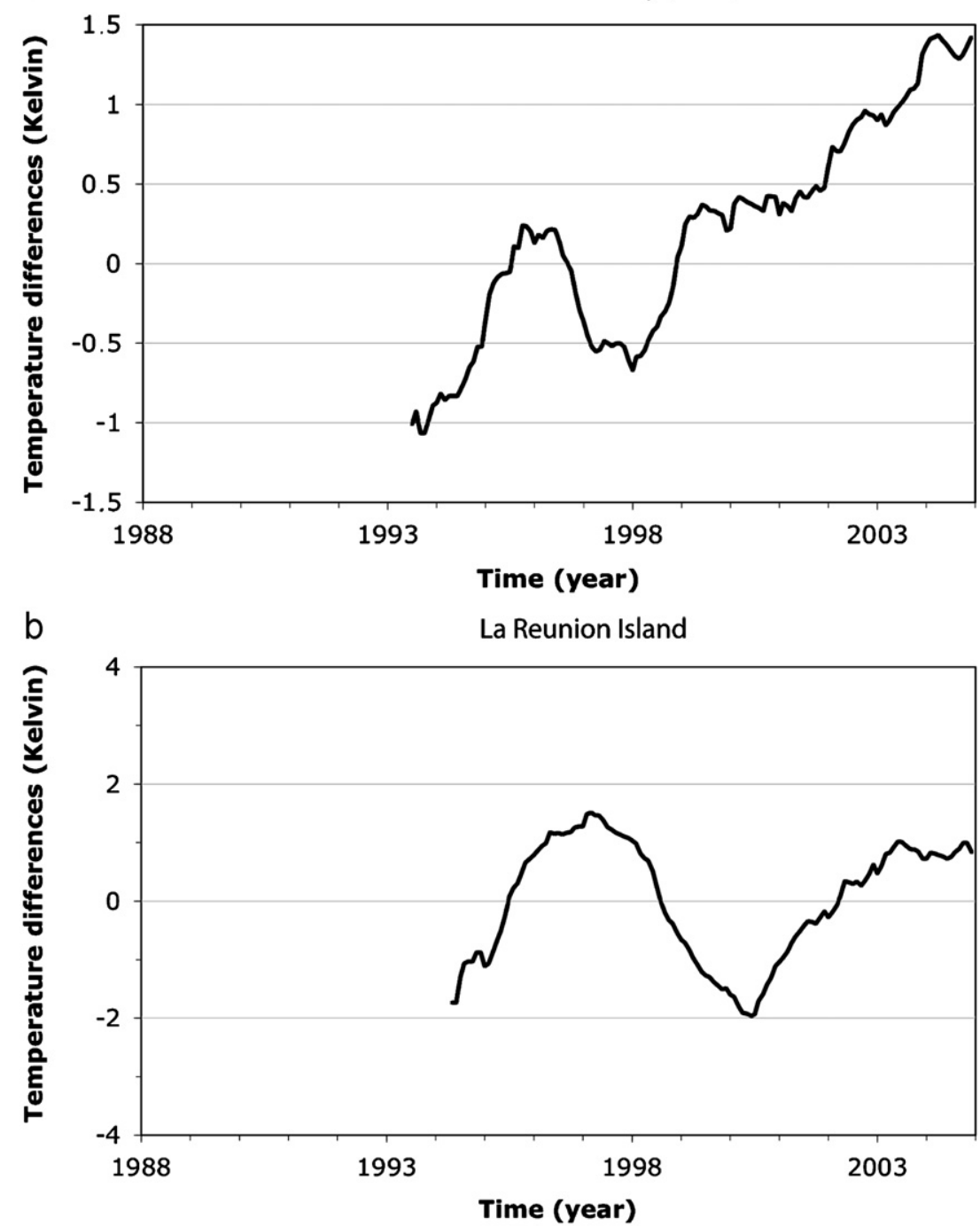

Fig. 9. Temperature differences between zonal monthly mean temperatures derived from SSU channel $36 \mathrm{X}$ and monthly means of weighted lidar profiles (Tlidar-TSSU) at tropical sites: (a) Mauna Loa and (b) La Réunion.

The comparisons with an SSU show that no obvious problems of discontinuities appear on the two longest lidar data series of TMF and OHP, except at the lowest altitude $(30 \mathrm{~km})$ in the beginning of both series. The reliability of trend estimates appears to be associated mainly with temporal sampling and changes of the integration period. This last limitation requires keeping the measurement time window unchanged even if it is strongly related to local weather and in contradiction to sampling effects.

\section{Vertical trends profile estimates}

Linear trends in the middle atmosphere temperature have been derived from the longest lidar series obtained at an OHP that exhibits a relatively good agreement with an SSU in the stratosphere, by using multi-regression analyses. This well known method takes into account the main components of the natural inter-annual variability, such as the solar cycle, the Quasi Biennial Oscillation (QBO), and aerosols injected in the stratosphere after major volcanic eruptions. Trends derived from the lidar series cover the upper stratospheric region overlapping the SSU range, but also provide additional information in the mesosphere, which is poorly documented over the long-term either from ground-based systems or space (Beig et al., 2003). The regression model was developed and adapted from the so-called Adaptative MOdel for UNambiguous Trend Survey(AMOUNTS) temperature trend model (Hauchecorne et al., 1991; Keckhut et al., 1995, 1999) of an LATMOS. The regression model used here includes a linear function related to solar activity ( $10.7 \mathrm{~cm}$ solar flux), and a proxy function associated with a large atmospheric oscillation of 28 months called QBO. Two QBO terms have been used to calculate amplitude $(d)$ and phase $(\varphi)$ based on the Singapore index provided by the Institut fur Meteorologie (Berlin, Germany), and an orthogonal term created by shifting the series by 7 months, i.e., about one quarter of the QBO period. However, several approaches have been tested for the computation of trends since they appear to present a breakdown around 1997. The first approach consists in two piecewise linear trends with a breakpoint change in 1997. The second one is a linear trend over the full period. Finally, the third one consists of a linear and a quadratic trend term and is described by the formula (1); it presents the advantage of not prescribing the breakpoint (as its origin is not clearly obvious), and to provide a smoother transition

$$
\begin{aligned}
T(t, z)= & a(z) \operatorname{trend}(t)+b(z) \operatorname{trend}(z)^{2}+c(z) \operatorname{solar}(t)+d(z) \\
& \times Q B O(t+\varphi(z))+\operatorname{residual}(t, z)
\end{aligned}
$$


where $t$ is the time, $z$ is the altitude, $T$ is the temperature, $a, b, c$, and $d$ are regression coefficients that depend on the altitude $z$, trend is the time-derivative (linear or quadratic), $Q B O$ is the equatorial wind and residual is the difference between the regression model and the data.

Tests using artificial signals have shown that small trend inflections can be reproduced by including a quadratic term in the statistical model (Kerzenmacher et al., 2006). Volcanic eruptions may also have a significant impact on the mean atmospheric temperature. A direct effect in the lower stratosphere and troposphere over tropical regions was unambiguously detected after major volcanic events such as the last Mount Pinatubo eruption (Labitzke and McCormick, 1992; Angell, 1997). Indirect effects such as those caused by the propagation of waves through a different vertical stability layer impact the global circulation even far from the place, where the direct forcing occurs (Rind et al., 1990; Keckhut et al., 1996). Periods after both major volcanic eruptions El Chichon (1982, March-April) and Mount Pinatubo (1991, April-June) have been removed from the data set to reduce the influence of these episodic events on the trend estimates. These periods depend on the aerosol loading and are, respectively, fixed at 8 and twenty 18 months for the El Chichon and Mt. Pinatubo volcanic eruptions, according to the SAGE observations (Sato et al., 1993).

Trends at mid-latitude have been estimated during for the summer period (April-September) exhibiting the smallest variability, and thus the best conditions to detect and quantify trends. Temperature trends derived from OHP data set over the full
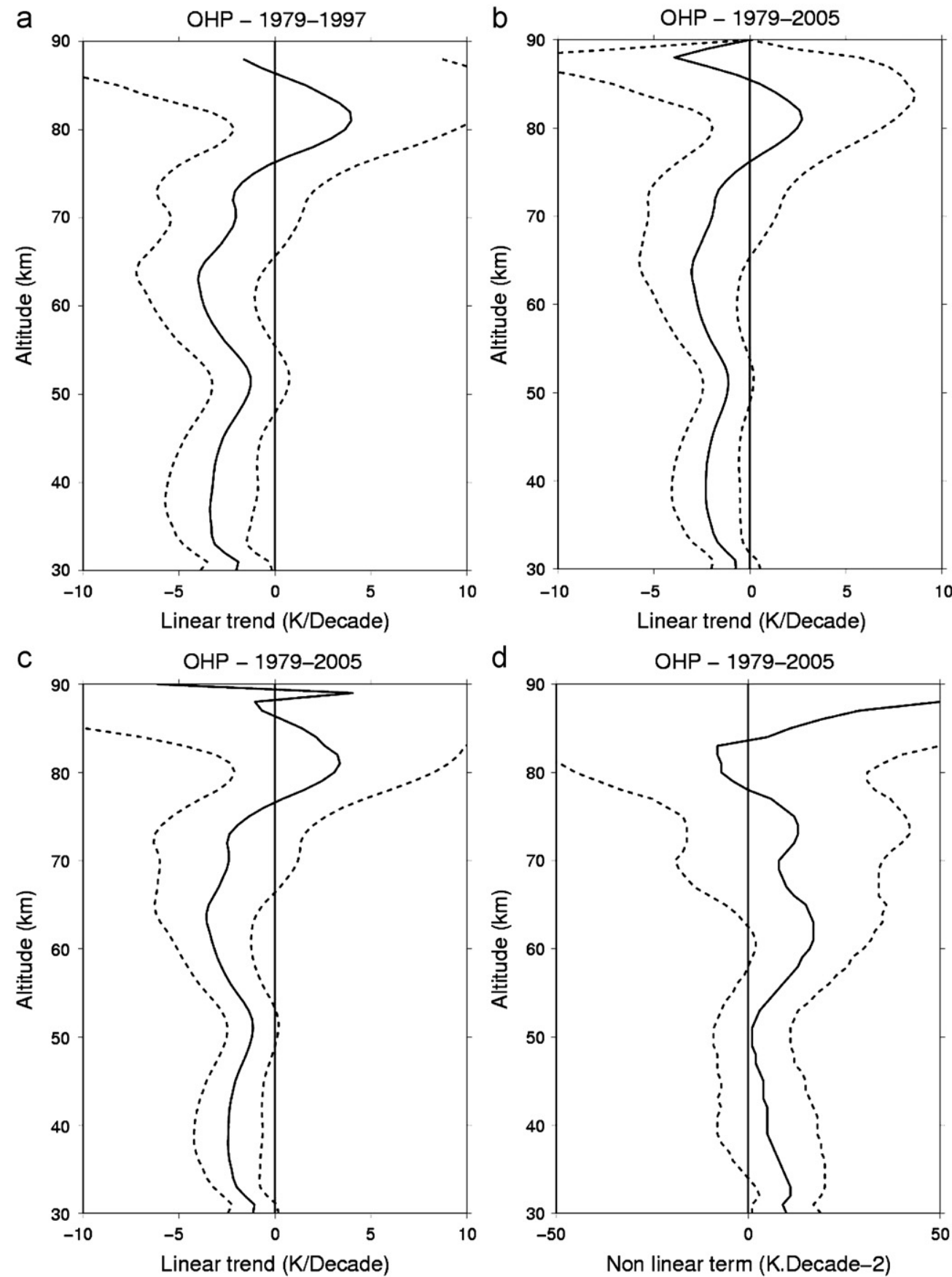

Fig. 10. Vertical profiles of temperature linear trends derived for the period 1979-2005, for the summer OHP series, for (a) two-piecewise trend analysis with a break point in 1997 and (b) monotonous linear trend analysis. A second trend analysis method includes (c) a linear term and (d) a quadratic term. 
period show a trend of $-2 \mathrm{~K} /$ decade in the $35-45 \mathrm{~km}$ altitude range, while the derived trend (using the second approach) is equal to $-2.5 \mathrm{~K} /$ decade around $65 \mathrm{~km}$ (Fig. 10b); notice a slight positive trend at $80 \mathrm{~km}$. These values are smaller compared to those observed using the two piecewise approach with a breakpoint at 1997 (Fig. 10a). This result is expected, while a breakdown has been noticed in all the data sets. When the quadratic term is introduced into the analysis, the linear trend term (Fig. 10c) is very similar to the estimate using the two-piecewise trend method. The quadratic terms are significant in the midstratosphere $(30-35 \mathrm{~km})$ and just above stratosphere $(60 \mathrm{~km})$ showing that this extra term is adapted to take into account the cooling rate inflection when the exact time of the change is not known. During winter, the vertical shape of trends is similar to those in summer (not shown), although slightly larger in the mesosphere and smaller in the upper stratosphere, but anyway less significant due to the larger monthly variability

\section{Discussion and conclusions}

The temperature lidars deployed within the NDAAC, at very different locations around the globe and with a long-term commitment to continuous observation, show strong value for the validation of the temperature series assembled from the successive SSU experiments. Methodological problems associated with sampling effects and vertical weighting functions can explain some of the relatively large differences regarding expected trend amplitudes. The SSU data are unique temperature series that allows investigating global long-term changes; it shows a slowdown of the cooling rate in 1996-1998, also observed in the longest lidar series. The more recent lidar series show no trend for the recent decade in agreement with the SSU series. The HOH series show a large difference compared to OHP and SSU in the 1998-1999 period; however, the reason is not well understood. It could be due to a combined effect of sampling and noise, but our investigations do not reveal any sign of these effects; in addition, NCEP analyses seems to confirm a real difference of atmospheric origin. $\mathrm{HOH}$ and $\mathrm{OHP}$ temperature differences are further investigated in a recent study by Funatsu et al. (accepted for publication). The lidar operated in California shows a different behavior compared to the SSU series for the different SSU channels investigated. Long-term evolution indicates larger trends than the SSU and OHP series that are not explained by the SSU weighting function drift due to $\mathrm{CO}_{2}$ increase, and are most likely due to successive drifts in 1990 and 1999. No instrumental changes at TMF seem to explain such differences. Very likely, the non-zonal nature of atmospheric dynamics over the northern hemisphere and tidal effects can play a role, while NOAA platforms exhibit large orbit drifts. For the lowest levels, an OHP is probably biased by misalignment effects.

The tropical lidar stations reveal clear inter-annual differences for the channels covering the lowest altitude range (26, 36X). These differences are not the same for the two stations, which are located in the different hemispheres and at different longitudes, and are probably associated with inter-annual internal dynamical effects such as QBO or an ENSO that differs slightly with longitude. No obvious instrumental problems have been identified in the longest lidar data series through the auxiliary lidar proxies, and therefore preliminary trends have been derived.

Trends derived from lidars reveal a clear change in the cooling rate in the period 1996-1998. Trends for the period up to 2005 are smaller than those calculated for the data sets limited to 1997. The reason for such slowdown of the trends is not clear nor does its amplitude; moreover the slowdown is not in agreement with the ozone recovery that occurs later compared to temperature. The cooling is partly due to ozone decrease and greenhouse gas increase; hence the disappearance of trend is not understood. While this temporal evolution is qualitatively confirmed by lidars, the origin of this breakdown needs to be investigated with numerical models. Two methods to derive such non-linear trends have been tested. While the date of such breakdown of the trend is not known, the multi-regression analysis using a quadratic term allows the derivation of both the linear cooling and the trend curvature. In the winter mesosphere the response was larger, while the winter stratosphere had smaller response. There is obviously a contribution of the atmospheric dynamics; in fact OHP shows nearly no trend, though a positive curvature related to a slowdown of the cooling is noted. In the lower mesosphere $(55-65 \mathrm{~km})$, a cooling of 3-5 K/decade has been derived with a significant positive curvature. In the upper mesosphere $(70-75 \mathrm{~km})$, there is a second cooling maximum of 3-6 K/decade. Near the mesopause, the results are less significant and the trends tend to be positive and the curvature negative. The cooling trends derived from GCMs within the CCMVal project (Chemistry Climate Model Validation) for the period 1980-1990 (that cover mainly the monotonous cooling period) are slightly smaller than that of the OHP trend estimates. It will be valuable to compare temperature trends on a regional rather than zonal scale and investigate the variability of trends according to longitudes.

While some uncertainties still remain, this study suggests that further work needs to be performed to take better advantage of the combined use of both ground-based networks and successive space instruments. Zonal means are probably not well adapted for this purpose, because the large inter-annual variability and anthropogenic temperature trends are not purely zonally symmetric. Whereas the use of zonal means reduces the effect of tidal interferences, orbit changes or drifts remain a big issue in this altitude range. Lidar stations sampling different longitudes for the main latitude bands (polar, middle, and tropical latitudes) are required for a pertinent middle atmospheric monitoring. Lidar instruments provide useful references, and the comparisons presented here suggest that accurate profiles in the mesosphere are required (even for upper stratospheric satellite measurements), because the weighting functions embrace a large part of the mesosphere. The challenge will be yet more complicated as SSU instruments will not anymore be available and being replaced by different space techniques such as the AMSU. Lidars can provide useful monthly temperature series; however, longterm monitoring requires enduring stability of the time sampling (number of days and time of the measurement). This is a challenge since lidar operations depend on weather.

The synergy between space observations using successive similar payloads and ground references at several places around the globe seems to be a good strategy for temperature monitoring, yet this study suggests that we should improve the effectiveness of the system. A few recommendations can then be proposed to reduce uncertainties in the future when comparing groundbased lidar and space observations:

1. Sampling appears to be a potential source of uncertainties mainly because lidar operations depend on weather, instrumental failures and irregular time-of-measurements associated with tides. Maintaining as far as possible the time (hours) of measurements and integration time as well as a regular and frequent sampling is probably the main recommendation. In addition, the data set can be filtered to exclude measurements outside a certain time window in the NDACC archive.

2. The effect of under-sampling should be further investigated with shorter series exhibiting good continuity. This can be done with an AMSU series as in Funatsu et al. (2008). 
Analysis should take into account under-sampling effects and focus on anomaly distributions mainly in winter when stratospheric warming occur and have a strong influence on the monthly mean. Adequate interpolation should be sought to fill up missing data in the computation of monthly means.

3. While bias should be reduced, random measurement uncertainties should remain unchanged. This can be done by reducing the delay of repairs and getting commercial parts, mainly the laser emitter. Both laser power and vertical resolution improvements should be avoided to reduce the causes of discontinuity.

4. For satellite-lidar comparisons, only coincident observations should be considered. Usually lidar data has been vertically averaged according to the weighting function, but an alternative approach that can be adopted consists in comparisons at the level of the maximum of the weighting function. This procedure would avoid including lidar data with larger errors corresponding to higher altitude levels and reduce the effects due to the differences of lidar capabilities.

5. SSU series are provided in zonal average to reduce discontinuities. However, such averaging is not satisfactory for comparison with local ground-based measurements. In this respect, AMSU series in providing local measurements are more suitable.

6. Since the first NCEP data set (Keckhut et al., 1996), NOAA has processed SSU differently following the Nash methodology. A large uncertainty is still associated with SSU vertical weighting functions. Their evolution due to $\mathrm{CO}_{2}$ increase has been quantified and need to be corrected (Shine et al., 2008). As NOAA plans to reassess the SSU series, the lidar-network will help to evaluate the improvements of the new analysis.

\section{Acknowledgements}

The data used in this study were obtained as part of the Network for the Detection of Atmospheric Composition Change (NDACC) and are publicly available (see http://www.ndacc.org). The authors thank Dr. Fei Wu for the SSU data preparation. The measurements at TMF and MLO were carried out by the Jet Propulsion Laboratory, California Institute of Technology under an agreement with the National Aeronautics and Space Administration. The measurements at OHP, and La Réunion were carried out as a National observing system carried out by Institut National des Sciences de l'Univers (INSU) and coordinated by Observatoire de Versailles-Saint Quentin (OVSQ-IPSL) performed within the Service d'Observation framework with the additional support of CNES and ADEME.

This work was initiated through the SPARC Stratospheric Temperature Trend Assessment group lead by Dr. W. Randel (http://www.atmosp.physics.utoronto.ca/SPARC/initiatives NEW2005Detection.html) and was partly supported by the European Commission through the Global Earth Observation and Monitoring (GEOmon—http://www.geomon.eu/) Integrated Project under the 6th Framework Program (Contract no. FP6-2005Global-4-036677). It is also part of the COST Action ES0702: European Ground-Based Observations of Essential Variables for Climate and Operational Meteorology (EG-CLIMET).

\section{References}

Angell, J.K., 1997. Stratospheric warming due to Agung, El Chichoon, and Pinatubo taking into account the quasi-biennial oscillation. J. Geophys. Res. 102, 9479-9485.

Austin, J., Wilson, J., Ailyoshi, H., Bekki, S., Butchart, N., Claud, C., Forster, P., Garcia, R.R., Gillet, N.P., Keckhut, P., Lagematz, U., Manzini, E., Nagashima, T., Randel, W.J., Rozanov, E., Shepherd, T.G., Shibata, K., Shine, K.P., Struthers, H.,
Thompson, S., Wu, F., Yoden, S., 2009. Coupled chemistry, climate model simulations of stratospheric temperatures and their trends for recent past. Geophys. Res. Lett. 36, L13809 doi:10.1029/2009GL038462.

Battrick, B., 2005. Global earth observation system of systems GEOSS: 10-year implementation plan reference document. Noordwijk: ESA publisher (issn: 0379-6566; 1284).

Beig, G., Keckhut, P., Lowe, R.P., Robel, R.G., Mlynczak, M.G., Scheer, J., Fomichev, V.I., Offermann, D., French, W.J.R., Shepherd, M.G., Semenov, A.I., Remsberg, E.E., She, C.Y., Lübken, F.J., Bremer, J., Clemesha, B.R., Stegman, J., Sigernes, F., Fadnavis, S., 2003. Review of mesospheric temperature trends. Rev. Geophys. 41 (4), 1015. doi:10.1029/2002RG000121.

Brindley, H.E., Geer, A.J., Haries, J.E., 1999. Climate variability and trends in SSU radiances: a comparison of model predictions and satellite observations in the middle stratosphere. J. Clim. 12, 3197-3219.

Cagnazzo, C., Claud, C., Hare, S., 2006. Aspects of stratospheric long-term changes induced by ozone depletion. Clim. Dyn. 27, 101-111. doi:10.1007/s00382006-0120-1.

Charlton, A.J., Polvani, L.M., 2007. A new look at stratospheric sudden warmings I: climatology and modelling benchmarks. J. Clim. 20, 449-469.

Eyring, V., et al., 2006. Assessment of temperature, trace species, and ozone in chemistry-climate model simulations of the recent past. J. Geophys. Res. 111, D22308. doi:10.1029/2006JD007327.

Finger, F.G., Gelman, M.E., Wild, J.D., Chanin, M.L., Hauchecorne, A., Miller, A.J., 1993. Evaluation of NMC upper-stratospheric temperature analyses using rocketsonde and lidar data. Bull. Am. Meteorol. Soc. 74, 789-799.

Funatsu, B.M., Claud, C., Keckhut, P., Hauchecorne, A., 2008. Cross-validation of AMSU and lidar for long-term upper-stratospheric temperature monitoring. J. Geophys. Res. 113, D23108. doi:10.1029/2008JD010743.

Funatsu, B.M., Claud, C., Keckhut, P., Steinbrecht, W., Hauchecorne, A. Investigations of stratospheric temperature regional variability with lidar and AMSU. J. Geophys. Res., accepted for publication.

Gelman, M.E., Miller, A.J., Johnson, K.W., Nagatani, R.M., 1986. Detection of longterm trends in global stratospheric temperature from NMC analysis derived from NOAA satellite data. Adv. Space Res. 6, 17-26.

Hauchecorne, A., Chanin, M.L., 1980. Density and temperature profiles obtained by lidar between 35 and $70 \mathrm{~km}$. Geophys. Res. Lett. 7, 565-568.

Hauchecorne, A., Chanin, M.L., Keckhut, P., 1991. Climatology and trends of the middle atmospheric temperature $(33-87 \mathrm{~km})$ as seen by Rayleigh lidar over the south of France. J. Geophys. Res. 96, 15297-15309.

Keckhut, P., Hauchecorne, A., Chanin, M.L., 1993. A critical review of the database acquired for the long term surveillance of the middle atmosphere by the French Rayleigh lidars. J. Atmos. Ocean. Technol. 10, 850-867.

Keckhut, P., Hauchecorne, A., Chanin, M.L., 1995. Midlatitude long-term variability of the middle atmosphere: trends and cyclic and episodic changes. J. Geophys. Res. 100 18.887-18.897.

Keckhut, P., Gelman, M.E., Wild, J.D., Tissot, F., Miller, A.J., Hauchecorne, A., Chanin, M.L., Fishbein, E.J., Gille, J., Russell III, J.M., Taylor, F.W., 1996. Semidiurnal and diurnal temperature tides $(30-55 \mathrm{~km})$ : climatology and effect on UARS-lidar data comparisons. J. Geophys. Res. (special issue on UARS Data Validation) 101, 10299-10310.

Keckhut, P., Schmidlin, F.J., Hauchecorne, A., Chanin, M.L., 1999. Trend estimates from US rocketsondes at low latitude stations (8S-34N), taking into account instrumental changes and natural variability. J. Atmos. Sol. Terr. Phys. 51, 447-459.

Keckhut, P., Kodera, K., 1999. Long-term changes of the upper stratrosphere as seen by rocketsondes at Ryori $\left(39^{\circ} \mathrm{N}, 141^{\circ} \mathrm{E}\right)$. Ann. Geophys. 17, 1210-1217.

Keckhut, P., Wild, J.D., Gelman, M., Miller, A.J., Hauchecorne, A., 2001. Investigations on long-term temperature changes in the upper stratosphere using lidar data and NCEP analyses. J. Geophys. Res. 106, 7937-7944.

Keckhut, P., McDermid, I.S., Swart, D.P.J., McGee, T., Godin-Beekmann, S., Adriani, A., Barnes, J., Baray, J.-L., Bencherif, H., Claude, H., Riocco, G., Hansen, G., Hauchecorne, A., Leblanc, T., Lee, C.H., Pal, S., Megie, G., Nakane, H., Neuber, R., Steinbrecht, W. Thayer, J. 2004. Review of ozone and temperature lidar validations performed within the framework of the network for the detection of stratospheric change. J. Environ. Monit. 6, 721-733.

Keckhut, P., Cagnazzo, C., Chanin, M.L., Claud, Hauchecorne, A., 2005. The 11-year solar-cycle in the temperature in the upper-stratosphere and mesosphere: part I assessment of observations. J. Atmos. Terr. Sol. Phys. 67, 940-947. doi:10.1016/j.jastp.2005.01.008.

Kerzenmacher, T.E., Keckhut, P., Hauchecorne, A., Chanin, M.L., 2006. Methodological uncertainties in multi-regression analyses of middle-atmospheric data series. J. Environ. Monit. 8, 682-690. doi:10.1039/b603750j.

Kokin, G.A., Lysenko, E.V., Rosenfeld, S.X., 1990. Temperature changes in the stratosphere and mesosphere during 1964-1988 based on rocket sounding data. Izvestia Atmos. Ocianic Phys. 26, 702-710.

Kubicki, A., Keckhut, P. Chanin, M.-L., Golitsyn, G, Lysenko, E., 2007. Temperature trends in the middle atmosphere as seen by historical Russian rocket launches: part 2, Heiss Island $\left(80.6^{\circ} \mathrm{N}, 58^{\circ} \mathrm{E}\right)$. J Atmos. Sol. Terr. Phys. 70, 145-155, doi:10.1016/j.jastp.2007.09.010.

Kubicki, A., Keckhut, P., Chanin, M.L., Hauchecorne, A., Lysenko, E., Golitsyn, G.S., 2006. Temperature trends in the middle atmosphere as seen by historical Russian rocket launches: part 1 , Volgograd $\left(48.68^{\circ} \mathrm{N}, 44.35^{\circ} \mathrm{E}\right)$. J. Atmos. Sol. Terr. Phys. 68, 1075-1086.

Kurylo, M.J., Solomon, S., 1990. Network for the Detection of Stratospheric Change: a Status and Implementation Report. NASA Upper Atmosphere Research Program and NOAA Climate and Global Change Program (NASA), Washington, D.C. 
Labitzke, K., McCormick, M.P., 1992. Stratospheric temperature increases due to Pinatubo aerosols. Geophys. Res. Lett. 19 (2), 207-210, doi:10.1029/ 91GL02940.

Leblanc, T., McDermid, I.S., Hauchecorne, A., Keckhut, P., 1998. Evaluation of optimization of lidar temperature analysis algorithms using simulated data. J. Geophys. Res. 103, 6177-6187.

Leblanc, T. McDermid, I.S., Ortland, D.A., 1999a. Lidar observations of the middle atmospheric thermal tides and comparison with the high-resolution Doppler imager and global scale wave model. 1. Methodology and winter observations at Table Mountain (34.4 N). J. Geophys. Res. 104, 11917-11929.

Leblanc, T., McDermid, I.S., Ortland, D.A., 1999b. Lidar observations of the middle atmospheric thermal tides and comparison with the high-resolution Doppler imager and global scale wave model. 2. October observations at Mauna Loa $\left(19.5^{\circ} \mathrm{N}\right)$. J. Geophys. Res. 104, 11931-11938.

Li, T., Leblanc, T., McDermid, I.S., 2008. Interannual variations of middle atmospheric temperature as measured by the JPL lidar at Mauna Loa Observatory Hawaii $\left(19.5^{\circ} \mathrm{N}, 155.6^{\circ} \mathrm{W}\right)$. J. Geophys. Res. 113, D14109. doi:10.1029/ 2007JD009764.

McDermid, I.S., Godin, S., Lindquist, L.O., 1990. Ground-based laser DIAL system for long-term measurements of stratospheric ozone. Appl. Opt. 29, 3603-3612.

Morel, B., Bencherif, H., Keckhut, P., Baldy, S., Hauchecorne, A., 2002. Evidence of tidal perturbations in the middle atmosphere over southern tropics as observed by Rayleigh lidar. J. Atmos. Sol. Terr. Phys. 64, 1979-1988.

Nash, J., Forrester, G.F., 1986. Long-term monitoring of stratospheric temperature trends using radiance measurements obtained by the TIROS-N series of NOAA spacecraft. Adv. Space Res. 6, 37-44.

Nash, E.R., Newman, P.A., Rosenfield, J.E., Schoeberl, M.R., 1996. An objective determination of the polar vortex using Ertel's potential vorticity. J. Geophys. Res. 101, 9471-9478.

Nash, J., 1988. Extension of explicit radiance observations by the stratospheric sounding unit into the lower stratosphere and lower mesosphere. Q. J. R. Meteorol. Soc. 114, 1153-1171.

Ramaswamy, V., Chanin, M.L., Angell, J., Barnett, J., Gaffen, D., Gelman, M., Keckhut, P., Kolshelkov, Y., Labitzke, K., Lin, J.-J.R., O'Neill, A., Nash, J., Randel, W., Rood, R. Shine, K., Shiotani, M., Swinbank, R., 2001. Stratospheric temperature changes: observations and model simulations. Rev. Geophys. 39, 71-122.

Randel, W., Udelhofen, P., Fleming, E., Geller, M., Gelman, M., Hamilton, K., Karoly, D., Ortland, D., Pawson, S., Swinbank, R., Wu, F., Baldwin, M., Chanin, M.L., Keckhut, P., Labitzke, K., Remsberg, E., Simmons, A., Wu, D., 2004. The SPARC intercomparison of middle-atmosphere climatologies. J. Clim. 17, 986-1003.
Randel, W.J., Shine, K., Austin, J., Barnett, J., Claud, C., Gillett, N.P., Keckhut, P., Langematz, U., Lin, R., Long, C., Mears, C., Miller, A.J., Nash, J., Seidel, D.J. Thompson, D.W.J., Wu, F., Yoden, S., 2009. An update of observed stratospheric temperature trends. J. Geophys. Res. 114, D02107. doi:10.1029/2008JD010421.

Rind, D., Suozzo, R., Balanchandra, N.K., Prather, M.J., 1990. Climate change and the middle atmosphere: I, the doubled $\mathrm{CO}_{2}$ climate. J. Atmos. Sci. 47, 475-494.

Sato, M., Hansen, J.E., McCormick, M.P., Pollack, J.B., 1993. Stratospheric aerosol optical depth, 1850-1990. J. Geophys. Res. 98, 22987-22994.

Shine, K.P., Barnett, J.J., Randel, W.J., 2008. Temperature trends derived from stratospheric sounding unit radiances: the effect of increasing $\mathrm{CO}_{2}$ on the weighting function. Geophys. Res. Lett. 35, L02710. doi:10.1029/2007GL032019.

Singh, U.N. Keckhut, P. McGee, T. Gross, M.R., Hauchecorne, A., Fishbein, E.F. Waters, J.W., Gille, J.C., Roche, A.E., Russell III, J.M., 1996. Stratospheric temperature measurements by two collocated NDSC lidars at OHP during UARS validation campaign. J. Geophys. Res. (special issue on UARS Data Validation) 101, 10287-10298

Steinbrecht, W., Rothe, K.W., Walther, H., 1989. Lidar setup for daytime and nighttime probing of stratospheric ozone and measurements in polar and equatorial regions. Appl. Opt. 28, 3616-3624.

Steinbrecht, W., et al., 2006. Long-term evolution of upper stratospheric ozone at selected stations of the network for the detection of stratospheric change (NDSC). J. Geophys. Res. 111, D10308. doi:10.1029/2005JD006454.

Steinbrecht, W., McGee, T.J., Twigg, L.W., Claude, H., Schönenborn, F., Sumnicht, G.K. Silbert, D., 2009. Intercomparison of stratospheric ozone and temperature profiles during the October 2005 Hohenpeißenberg Ozone Profiling Experiment (HOPE). Atmos. Meas. Tech. 2, 125-145. doi:10.5194/amt-2-125-2009.

Thrane, E.V., von Zahn, U., 1995. ALOMAR - a new facility for middle atmosphere research at arctic latitudes. J. Geomagn. Geoelectr. 47, 921-928.

Werner, J., Rothe, K.W., Walther, H., 1983. Monitoring of the stratospheric ozone layer by laser radar. Appl. Phys. B 32, 113-118.

Wild, J.D., Gelman, M.E., Miller, A.J., Chanin, M.L., Hauchecorne, A., Keckhut, P. Farley, R., Dao, P.D., Gobbi, G.P., Adriani, A., Coneduti, F., McDermid, I.S. McGee, T.J., Fishbein, E.F., 1995. Comparison of stratospheric temperature from several lidars using NMC and MLS data as transfer reference. J. Geophys. Res. 100 11105-1.111.

WMO (World Meteorological Organization), 2007. Scientific Assessment of Ozone Depletion: 2006, Global Ozone Research and Monitoring Project-Report no. 50. Geneva, 572pp.

Zhang, X., Forbes, J.M., Hagan, M.E., Russell, J.M., Palo, S.E., Mertens, C.J., Mlynczak, M.G. 2006. Monthly tidal temperatures 20-120 km from TIMED/SABER. J. Geophys. Res. 111, A10S08. doi:10.1029/2005JA011504. 